\title{
Dibenzoanthradiquinone Building Blocks for the Synthesis of Nitrogenated Polycyclic Aromatic Hydrocarbons.
}

Jose I. Martínez, ${ }^{\dagger}$ Juan P. Mora-Fuentes, ${ }^{\dagger}$ Marco Carini, ${ }^{\dagger}$ Akinori Saeki, ${ }^{1, \pm}$ Manuel Melle-Franco and Aurelio Mateo-Alonso*i,*.

$\dagger$ POLYMAT, University of the Basque Country UPV/EHU, Avenida de Tolosa 72, 20018 Donostia-San Sebastian, Spain. 1Department of Applied Chemistry, Graduate School of Engineering, Osaka University, 2-1 Yamadaoka, Suita, Osaka 5650871, Japan. \pm PRESTO, Japan Science and Technology Agency (JST), 4-1-8 Honcho, Kawaguchi, Saitama 332-0012, Japan. \| CICECO-Aveiro Institute of Materials, University of Aveiro 3810-193 Aveiro, Portugal. \$lkerbasque, Basque Foundation for Science, Bilbao, Spain. 
Optoelectronic and electrochemical characterization

Synthetic procedures

${ }^{1} \mathrm{H}$ and ${ }^{13} \mathrm{C}$ NMR spectra

IR Spectra

X-Ray crystallography data
Figure S1. NICS of compounds $\mathbf{3 a}, \mathbf{3 b}, \mathbf{4}$ and $\mathbf{5}$.

S 4

Figure S2. $\mathrm{CH}_{2} \mathrm{Cl}_{2}$ solutions of $\mathbf{3 b}, \mathbf{4}$ and $\mathbf{5}$ exposed to visible light (left) and UV light (right).

Figure S3. Calculated absorption spectrum using TD-DFT at the B3LYP$\mathrm{CH}_{2} \mathrm{Cl}_{2}-6-311+\mathrm{g}(2 \mathrm{~d}, \mathrm{p}) / \mathrm{B} 3 \mathrm{LYP}-6-31 \mathrm{~g}(\mathrm{~d}, \mathrm{p})$ level of compounds $\mathbf{3 a}, \mathbf{3 b}, \mathbf{4}$ and $\mathbf{5}$. Figure S4. FP-TRMC $\left(\lambda_{\mathrm{exc}}=355 \mathrm{~nm}\right)$ of a) $\left.\mathbf{3 a}, \mathrm{b}\right) \mathbf{3 b}$, c) $\mathbf{4}$ and d) $\mathbf{5}$.

Table S1. Summary of photophysical data and energy levels of compounds $\mathbf{3 a}$, $3 b, 4$ and 5 .

Table S2. First excitations TD-DFT at the B3LYP- $\mathrm{CH}_{2} \mathrm{Cl}_{2}-6-$ $311+\mathrm{g}(2 \mathrm{~d}, \mathrm{p}) / \mathrm{B} 3 \mathrm{LYP}-6-31 \mathrm{~g}(\mathrm{~d}, \mathrm{p})$ level of compounds $\mathbf{3 a}, \mathbf{3 b}, \mathbf{4}$ and $\mathbf{5}$.

Table S3. Half-wave, cathodic and anodic peak potentials of compounds $\mathbf{3 a}$, $3 b, 4$ and 5.

Table S4. Experimental energy levels of compounds 3a, 3b, 4 and 5.

Table S5. Orbitals eigenvalues at the B3LYP-CH $\mathrm{Cl}_{2}-6-311+\mathrm{g}(2 \mathrm{~d}, \mathrm{p}) / \mathrm{B} 3 \mathrm{LYP}-$ $6-31 \mathrm{~g}(\mathrm{~d}, \mathrm{p})$ level of theory of compounds $\mathbf{3 a}, \mathbf{3 b}, \mathbf{4}$ and $\mathbf{5}$.

.
Figure S32. Thermal ellipsoid plot for compound 3a at 50\% ellipsoid
contour probability.

Table S6. Crystal data and structure refinement for compound 3a.

Figure S33. Thermal ellipsoid plot for compound $\mathbf{3 b}$ at $50 \%$ ellipsoid contour probability.

Table S6. Crystal data and structure refinement for compound $\mathbf{3 b}$.

Figure S34. Thermal ellipsoid plot for compound 4 at 50\% ellipsoid contour probability.

Table S8. Crystal data and structure refinement for compound 4.

Figure S35. Thermal ellipsoid plot for compound $\mathbf{5}$ at $50 \%$ ellipsoid contour probability.

Table S9. Crystal data and structure refinement for compound $\mathbf{5}$.
S 5

S 6

S 7

S 8

S 10

S 11

S 12

S 13

S 14

S 18

S 31

S 32

S 32

S 32

S 34

S 34

S 36

S 36

S 38

S 38

S 40

References 


\section{GENERAL METHODS AND MATERIALS:}

Reagents for synthesis were, if not otherwise specified, purchased from Merck, Fluka, Acros or Fluorochem. Commercial chemicals and solvents were used as received. THF, DMF and toluene were dried using an Innovative Pure Solve solvent purification system.

Analytical thin layer chromatography (TLC) was done using aluminum sheets (20x20cm) pre-coated with silica gel RP-18W 60 F254 from Merck. Column chromatography was carried out using Silica gel $60(40-60 \mu \mathrm{m})$ from Scharlab.

If heating was required for reactions magnetic hot plate stirrer with a temperature sensor and an aluminum dry heating block attached was employed.

NMR spectra in solution were recorded on a Bruker Avance III $400 \mathrm{MHz}$ spectrometer at $298 \mathrm{~K}$ using partially deuterated solvents as internal standards. Coupling constants $(J)$ are denoted in $\mathrm{Hz}$ and chemical shifts $(\delta)$ in ppm. Multiplicities are denoted as follows: $\mathrm{s}=$ singlet, $\mathrm{d}=$ doublet, $\mathrm{t}=$ triplet, $\mathrm{m}=$ multiplet, $\mathrm{br}=$ broad. COSY and/or HSQC experiments were acquired to confirm precise molecular conformation and to assist in deconvoluting complex multiplet signals.

Mass Spectrometry experiments were recorded in a Ultraflex III (Bruker Daltonics) MALDI-ToF (frequency-tripled (355 nm) Nd:YAG laser) or UPLC-MS using ESI coupled to an TOF detector by Dr. Javier Calvo (CIC Biomagune).

ATR-FTIR spectra were recorded on a Bruker ALPHA ATR-IR spectrometer.

$\mathrm{X}$-ray data collections were performed in an Agilent Supernova diffractometer equipped with an Atlas CCD area detector, and a $\mathrm{CuK} \alpha$ micro-focus source with multilayer optics $(\lambda=1.54184 \AA$, $250 \mu \mathrm{m}$ FWHM beam size) by Dr. Leire Sanfelices (SGiker, University of the Basque Country). The quality of the crystals was checked under a polarizing microscope, and a suitable crystal or fragment was mounted on a Mitegen Micromount ${ }^{\mathrm{TM}}$ using Paratone- $\mathrm{N}$ inert oil and transferred to the diffractometer. The samples were kept at 150(10)K with a Oxford Cryosystems Cryostream 700 cooler.

Absorption spectra were recorded on a Perkin-Elmer Lambda 950 spectrometer.

Fluorescence spectra were recorded on a LS55 Perkin-Elmer Fluorescence spectrometer.

Electrochemical measurements were carried out on a Princeton Applied Research Parstat 2273 in a 3-electrode single compartment cell with glassy carbon disc working electrode, a platinum wire counter electrode and a silver wire pseudoreference electrode. All the potential values are reported versus the redox potential of the ferrocene/ferrocenium couple.

Time-resolved Microwave Conductivity (TRMC) was performed setting a film on a quartz substrate in a resonant cavity and probed by continuous microwaves at $\sim 9.1 \mathrm{GHz}$. The third harmonic generation (THG; $355 \mathrm{~nm}$ ) of a Nd:YAG laser (Continuum Inc., Surelite

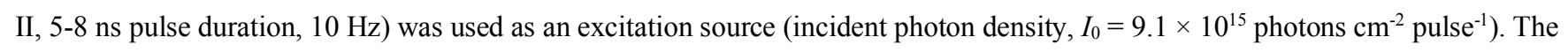
photoconductivity transient $\Delta \sigma$ was converted to the product of the quantum yield $(\phi)$ and the sum of the charge carrier mobilities, $\Sigma \mu(=\mu \mathrm{h}+\mu \mathrm{e})$ by $\phi \Sigma \mu=\Delta \sigma\left(\mathrm{e} I_{0} \mathrm{~F}_{\text {light }}\right)^{-1}$, where e and $\mathrm{F}_{\text {light }}$ are the unit charge of a single electron and the correction (or filling) factor, respectively. 
OPTOELECTRONIC AND ELECTROCHEMICAL CHARACTERIZATION:

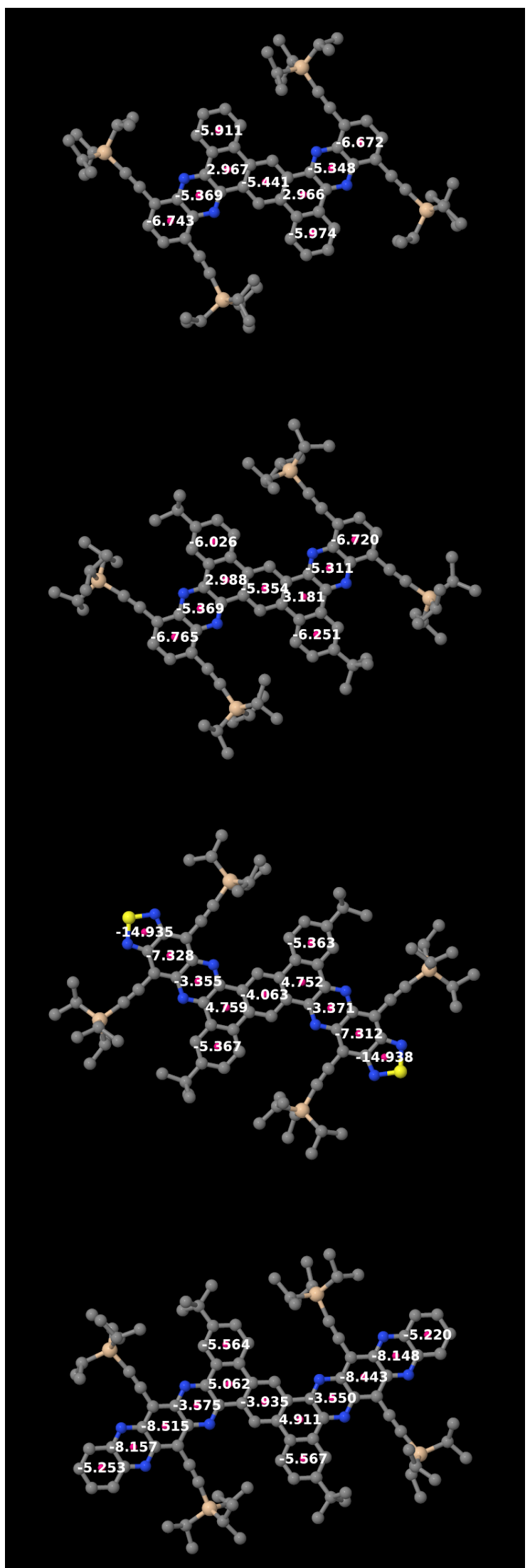

Figure S1. NICS of compounds $\mathbf{3 a}, \mathbf{3 b}, \mathbf{4}$ and $\mathbf{5}$. 


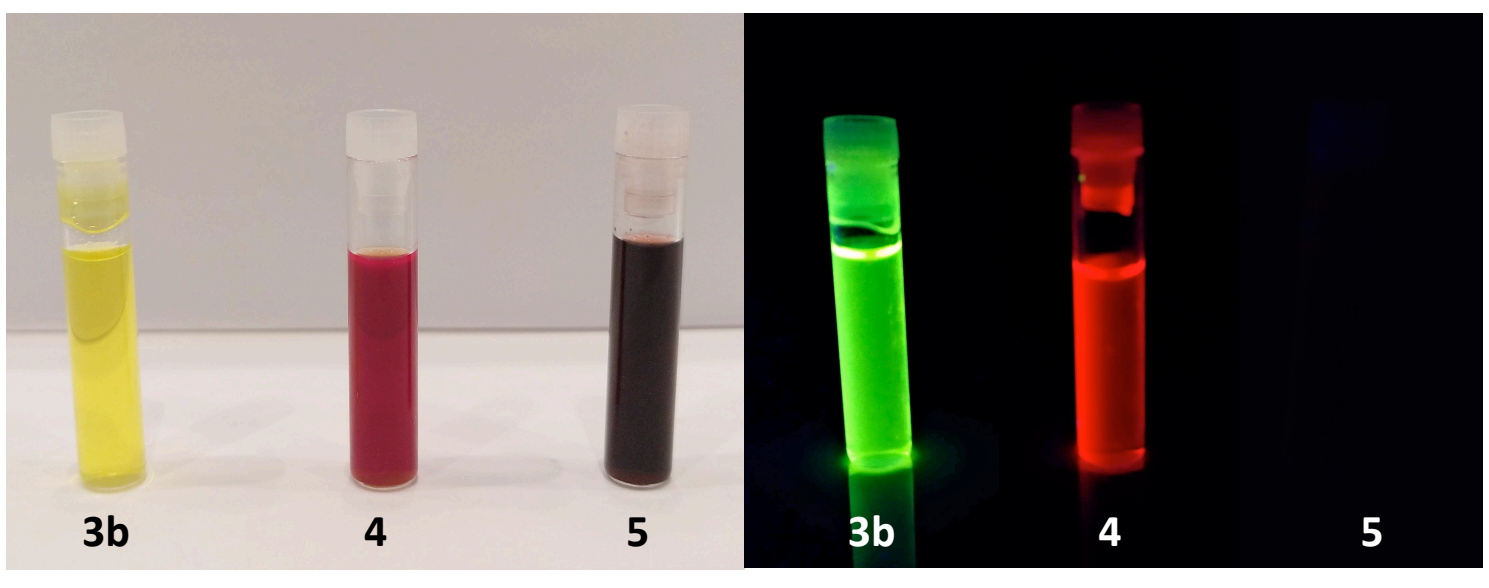

Figure S2. $\mathrm{CH}_{2} \mathrm{Cl}_{2}$ solutions of $\mathbf{3 b}, \mathbf{4}$ and $\mathbf{5}$ exposed to visible light (left) and UV light (right). 


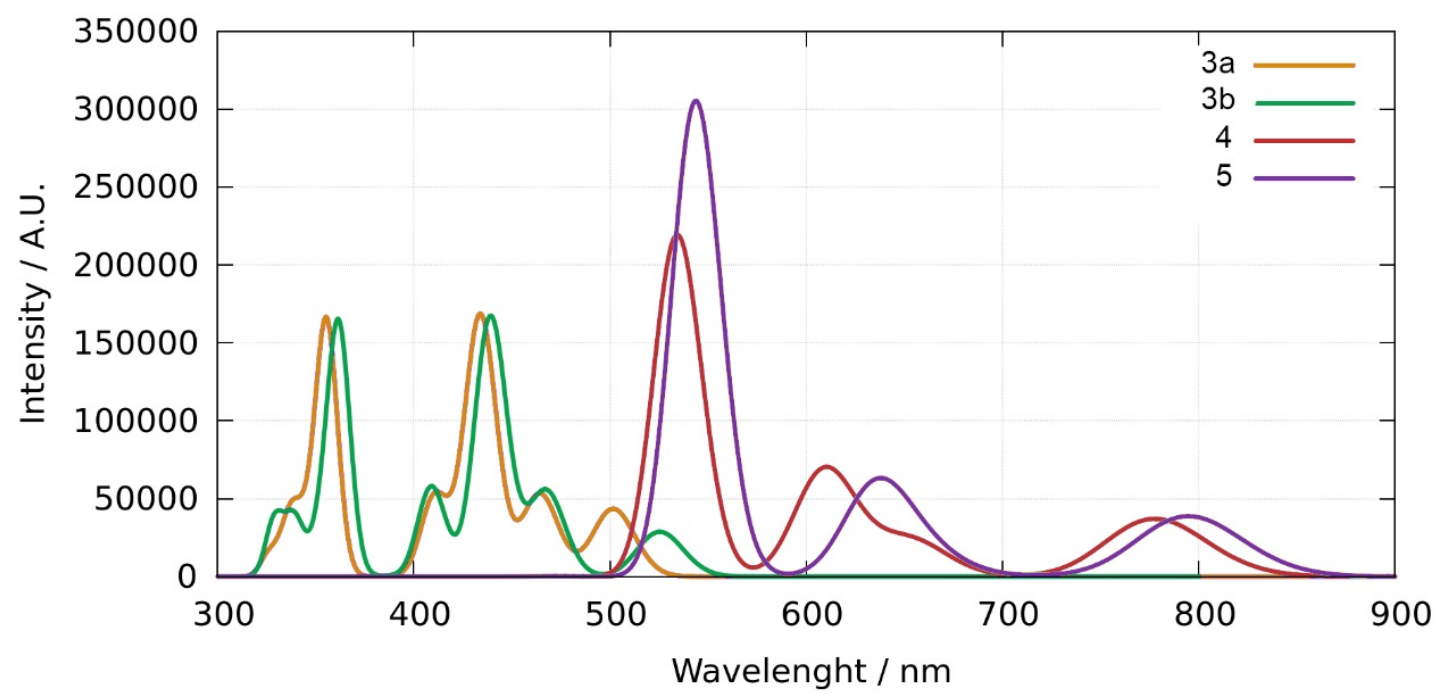

Figure S3. Calculated absorption spectrum using TD-DFT at the B3LYP-CH${ }_{2} \mathrm{Cl}_{2}-6-311+\mathrm{g}(2 \mathrm{~d}, \mathrm{p}) / \mathrm{B} 3 \mathrm{LYP}-6-31 \mathrm{~g}(\mathrm{~d}, \mathrm{p})$ level of compounds 3a, 3b, 4 and 5 . 
a)

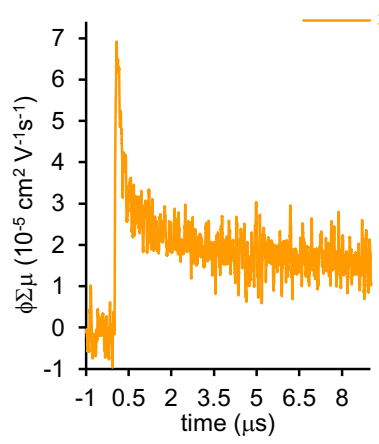

c)

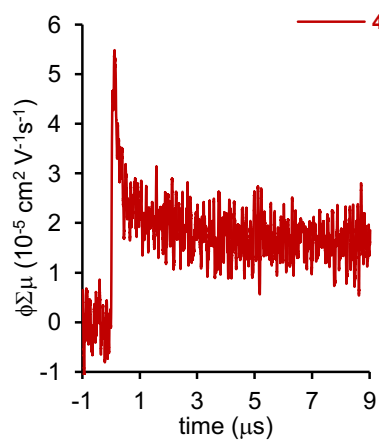

b)

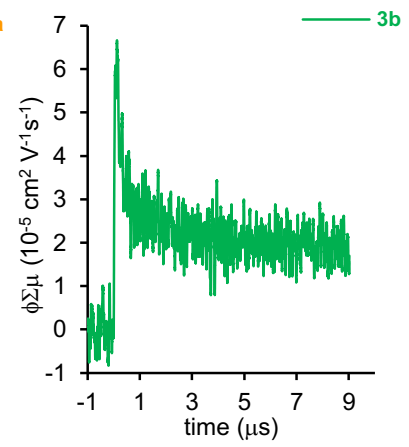

d)

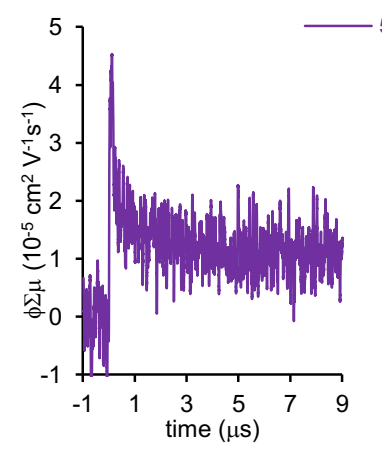

Figure S4. FP-TRMC ( $\left.\lambda_{\text {exc }}=355 \mathrm{~nm}\right)$ of a) 3a, b) 3b, c) 4 and d) 5 . 
Table S1. Summary of photophysical data and energy levels of compounds $3 a, 3 b, 4$ and 5 .

$\begin{array}{ccccccccc}\text { entry } & \text { compound } & \begin{array}{c}\lambda_{\text {max, abs, exp }} \\ (\mathrm{nm})\end{array} & \begin{array}{c}\lambda_{\text {max, abs, calc }} \\ (\mathrm{nm})^{[\mathrm{a}]}\end{array} & \begin{array}{c}\lambda_{\text {onset }} \\ (\mathrm{nm})\end{array} & \begin{array}{c}\lambda_{\max , \text { ems, exp }} \\ (\mathrm{nm})\end{array} & \begin{array}{c}\lambda_{\text {max, ems, calc }} \\ (\mathrm{nm})^{[\mathrm{a}]}\end{array} & \begin{array}{c}\text { Stokes' shift } \\ \left(\mathrm{cm}^{-1}\right)\end{array} & \begin{array}{c}\Phi_{f} \\ (\%)\end{array} \\ 1 & \text { 3a } & 456 & 501 & 471 & 470 & 515 & 6532 & 8.25 \pm 0.20^{[\mathrm{b}]} \\ 2 & \mathbf{3 b} & 472 & 525 & 489 & 502 & 540 & 12661 & 8.81 \pm 0.22^{[\mathrm{b}]} \\ 3 & \mathbf{4} & 620 & 777 & 640 & 632 & 810 & 3062 & 36.47 \pm 0.59^{[\mathrm{c}]} \\ 4 & \mathbf{5} & 659 & 795 & 681 & 670 & 827 & 2491 & 10.28 \pm 0.28^{[\mathrm{c}]}\end{array}$

[a] Calculated using TD-DFT at the B3LYP- $\mathrm{CH}_{2} \mathrm{Cl}_{2}-6-311+\mathrm{g}(2 \mathrm{~d}, \mathrm{p}) / \mathrm{B} 3 \mathrm{LYP}-6-31 \mathrm{~g}(\mathrm{~d}, \mathrm{p})$ level; [b] Calculated using 9,10-Diphenylanthracene (DPA) in cyclohexane as reference standard $;{ }^{1}[\mathrm{c}]$ Calculated using Oxacine 170 in EtOH as reference standard. ${ }^{2}$

Quantum yields $\Phi_{f, x}$ were calculated following the next equation:

$$
\Phi_{f, x}=\Phi_{f, s t} \cdot \frac{\mathrm{F}_{x} \cdot \mathrm{f}_{s t}\left(\lambda_{e x, s t}\right) \cdot \eta_{x}^{2}}{\mathrm{~F}_{s t} \cdot \mathrm{f}_{x}\left(\lambda_{e x, x}\right) \cdot \eta_{s t}^{2}}
$$

Where $\Phi_{\mathrm{f}, \mathrm{st}}$ stands for the quantum filed of the reference standard, $\mathrm{F}_{\mathrm{x}}$ for the measured fluorescence (area) of a solution at known concentration of products $3 \mathbf{a}, \mathbf{3 b}, \mathbf{4}$ or $\mathbf{5}$ at the excitation wavelength, $\mathrm{F}_{\mathrm{st}}$ for the measured fluorescence (area) of a solution at known concentration of the reference standard at the excitation wavelength, $\mathrm{f}_{x}\left(\lambda_{e x}\right) 1-10^{\mathrm{A}_{x}\left(\lambda_{e x}\right)}$ where $\mathrm{A}_{x}\left(\lambda_{e x}\right)$ stands for the absorbance of a solution at known concentration of products $\mathbf{3 a}, \mathbf{3 b}, \mathbf{4}$ or $\mathbf{5}$ at the excitation wavelength, $\mathrm{f}_{s t}\left(\lambda_{\text {ex }}\right)=1-10^{\mathrm{A}_{s t}\left(\lambda_{e x}\right)}$ where $\mathrm{A}_{s t}\left(\lambda_{e x}\right)$ stands for the absorbance of a solution at known concentration of the reference standard at the excitation wavelength, $\eta_{\mathrm{x}}$ is the index of refraction of the solvent of the solutions of compounds $\mathbf{3 a}, \mathbf{3 b}, \mathbf{4}$ or $\mathbf{5}$ and $\eta_{\mathrm{st}}$ is the index of refraction of the solvent of the solution of the reference standard.

The error was calculated as follows:

$$
\text { Error }=\frac{\sqrt{\sum_{i=n}^{n}\left(\Phi_{f, x_{i}}-\overline{\Phi_{f, x}}\right)^{2}}}{n}
$$

To measure quantum yield of 3a 9,10-Diphenylanthracene (DPA) was selected as reference standard $\left(\Phi_{f, D P A}=0.93\right)^{1}$ at $7.42 \times 10^{-07} \mathrm{~mol} \cdot \mathrm{L}^{-1}$ in cyclohexane $\left(\eta_{c y}=1.45\right)$. The excitation wavelength was set at $340 \mathrm{~nm}$ and 3 solutions at different concentrations of 3a in $\mathrm{CHCl}_{3}\left(\eta_{\mathrm{CHCl}_{3}}=1.42\right)$ were analyzed:

\begin{tabular}{lll} 
entry & $\begin{array}{l}\text { Concentration } \\
\left(\mathrm{x} 10^{-7} \mathrm{~mol} \cdot \mathrm{L}^{-1}\right)\end{array}$ & $\begin{array}{l}\Phi_{f, 3 a} \\
(\%)\end{array}$ \\
\hline 1 & 5.87 & 8.68 \\
2 & 4.40 & 8.22 \\
3 & 2.94 & 7.85
\end{tabular}

The quantum yield of $\mathbf{3 a}$ is expressed as the average of the three measurements and the error associated:

$$
\overline{\Phi_{f, 3 a}}=8.25 \pm 0.20
$$


To measure quantum yield of 3b 9,10-Diphenylanthracene (DPA) was selected as reference standard $\left(\Phi_{f, D P A}=0.93\right)^{1}$ at $7.42 \mathrm{x}$ $10^{-07} \mathrm{~mol} \cdot \mathrm{L}^{-1}$ in cyclohexane $\left(\eta_{c y}=1.45\right)$. The excitation wavelength was set at $345 \mathrm{~nm}$ and 3 solutions at different concentrations of $\mathbf{3 b}$ in $\mathrm{CHCl}_{3}\left(\eta_{\mathrm{CHCl}_{3}}=1.44\right)$ were analyzed:

\begin{tabular}{lll} 
entry & $\begin{array}{l}\text { Concentration } \\
\left(\mathrm{x} 10^{-7} \mathrm{~mol} \cdot \mathrm{L}^{-1}\right)\end{array}$ & $\begin{array}{l}\Phi_{f, 3 \boldsymbol{b}} \\
(\%)\end{array}$ \\
\hline 1 & 7.97 & 8.29 \\
2 & 5.47 & 9.22 \\
3 & 3.63 & 8.92
\end{tabular}

The quantum yield of $\mathbf{3 b}$ is expressed as the average of the three measurements and the error associated:

$$
\overline{\Phi_{f, 3 b}}=8.81 \pm 0.22
$$

To measure quantum yield of 4 oxacine 170 was selected as reference standard $\left(\Phi_{f, \text { oxacine } 170}=0.58\right)^{2}$ at $3.54 \times 10^{-7} \mathrm{~mol} \cdot \mathrm{L}^{-1}$ in $\mathrm{EtOH}\left(\eta_{E t O H}=1.37\right)$. The excitation wavelength was set at $540 \mathrm{~nm}$ and 3 solutions at different concentrations of 4 in $\mathrm{CHCl}_{3}$ $\left(\eta_{\mathrm{CHCl}_{3}}=1.44\right)$ were analyzed:

\begin{tabular}{lll} 
entry & $\begin{array}{l}\text { Concentration } \\
\left(\times 10^{-6} \mathrm{~mol} \cdot \mathrm{L}^{-1}\right)\end{array}$ & $\begin{array}{l}\Phi_{f, 4} \\
(\%)\end{array}$ \\
\hline 1 & 0.32 & 36.76 \\
2 & 0.81 & 35.89 \\
3 & 1.62 & 34.82
\end{tabular}

The quantum yield of $\mathbf{4}$ is expressed as the average of the three measurements and the error associated:

$$
\overline{\Phi_{f, 4}}=36.47 \pm 0.59
$$

To measure quantum yield of 5 oxacine 170 was selected as reference standard $\left(\Phi_{\text {f,oxacine } 170}=0.58\right)^{2}$ at $3.54 \times 10^{-7} \mathrm{~mol} \cdot \mathrm{L}^{-1}$ in $\mathrm{EtOH}\left(\eta_{E t O H}=1.37\right)$. The excitation wavelength was set at $525 \mathrm{~nm}$ and 3 solutions at different concentrations of 5 in $\mathrm{CHCl}_{3}$ $\left(\eta_{\mathrm{CHCl}_{3}}=1.44\right)$ were analyzed:

\begin{tabular}{lll} 
entry & $\begin{array}{l}\text { Concentration } \\
\left(\mathrm{x} 10^{-6} \mathrm{~mol} \cdot \mathrm{L}^{-1}\right)\end{array}$ & $\begin{array}{l}\Phi_{f, 5} \\
(\%)\end{array}$ \\
\hline 1 & 1.60 & 10.69 \\
2 & 2.13 & 10.55 \\
3 & 3.20 & 9.61
\end{tabular}

The quantum yield of $\mathbf{4}$ is expressed as the average of the three measurements and the error associated:

$$
\overline{\Phi_{f, 5}}=10.28 \pm 0.28
$$




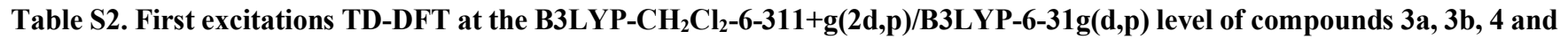
5.

\begin{tabular}{ccccc} 
entry & compound & energy $(\mathrm{eV})$ & energy $(\mathrm{nm})$ & osc. strength \\
1 & $\mathbf{3 a}$ & 2.47 & 501 & 0.20 \\
2 & $\mathbf{3 b}$ & 2.36 & 525 & 0.13 \\
3 & $\mathbf{4}$ & 1.59 & 777 & 0.17 \\
4 & $\mathbf{5}$ & 1.56 & 795 & 0.18 \\
\multicolumn{5}{c}{ All have a HOMO-LUMO transition contribution $\geq 90 \%}$.
\end{tabular}


Table S3. Half-wave, anodic and cathodic peak potentials of compounds 3a, 3b, 4 and 5.

\begin{tabular}{|c|c|c|c|c|c|c|c|c|c|c|}
\hline entry & compound & $\begin{array}{c}\mathrm{E}_{1 / 2, \text { red } 1} \\
(\mathrm{eV})\end{array}$ & $\begin{array}{c}E_{1 / 2, \text { red2 }} \\
(\mathrm{eV})\end{array}$ & $\begin{array}{c}E_{1 / 2, \text { red3 }} \\
(e V)\end{array}$ & $\begin{array}{c}\mathrm{E}_{\mathrm{pc}, \text { red1 }} \\
(\mathrm{eV})\end{array}$ & $\begin{array}{c}E_{a c, \text { red1 }} \\
(e V)\end{array}$ & 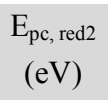 & $\begin{array}{c}\mathrm{E}_{\mathrm{ac}, \text { red2 }} \\
(\mathrm{eV})\end{array}$ & 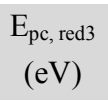 & $\begin{array}{c}E_{a c, \text { red3 }} \\
(e V)\end{array}$ \\
\hline 1 & $3 a$ & -1.52 & -1.72 & - & -1.54 & -1.50 & -1.76 & -1.67 & - & - \\
\hline 2 & $3 \mathbf{b}$ & -1.54 & -1.71 & - & -1.60 & 1.47 & -1.76 & -1.65 & - & - \\
\hline 3 & 4 & -0.93 & -1.04 & - & -097 & -0.92 & -1.08 & -1.00 & - & - \\
\hline 4 & 5 & -0.69 & -0.81 & -1.23 & -0.70 & -0.67 & -0.84 & -0.77 & -1.40 & -1.11 \\
\hline
\end{tabular}


Table S4. Experimental energy levels of compounds 3a, 3b, 4 and 5.

\begin{tabular}{|c|c|c|c|c|}
\hline entry & compound & $\begin{array}{c}E_{\mathrm{gap}(\mathrm{opt})^{[\mathrm{a}]}} \\
(\mathrm{eV})\end{array}$ & $\begin{array}{c}E_{(\text {LUMO })}{ }^{[\mathrm{b}]} \\
(\mathrm{eV})\end{array}$ & $\begin{array}{c}E_{(\text {(нОмО) }}{ }^{[\mathrm{c}]} \\
(\mathrm{eV})\end{array}$ \\
\hline 1 & 3a & 2.63 & -3.59 & -6.22 \\
\hline 2 & $3 b$ & 2.49 & -3.60 & -6.09 \\
\hline 3 & 4 & 1.94 & -3.92 & -5.86 \\
\hline 4 & 5 & 1.82 & -4.17 & -5.99 \\
\hline
\end{tabular}

[a] $\mathrm{E}_{\text {gap (opt) }}$ calculated from $\lambda_{\text {onset }}$ measured in chloroform; $[\mathrm{b}] \mathrm{E}_{(\mathrm{LUMO})}=-\mathrm{e}\left(4.8 \mathrm{~V}+\mathrm{E}_{\mathrm{Red}}\right) ;[\mathrm{c}] \mathrm{E}_{(\mathrm{HOMO})}=\mathrm{E}_{(\mathrm{LUMO})}-\mathrm{E}_{\mathrm{gap}(\mathrm{opt})}$. 
Table S5. Orbitals eigenvalues at the B3LYP-CH$-C_{2}-6-311+g(2 d, p) / B 3 L Y P-6-31 g(d, p)$ level of theory of compounds 3a, 3b, 4 and 5. All energies in $\mathrm{eV}$.

$\begin{array}{ccccccccccc}\text { entry } & \text { compound } & \text { LUMO+2 } & \text { LUMO+1 } & \text { LUMO } & \text { HOMO } & \text { HOMO-1 } & \text { HOMO-2 } & \text { gap } \\ 1 & \mathbf{3 a} & -1.95 & -2.74 & -3.05 & -5.96 & -6.09 & -6.21 & 2.91 \\ 2 & \mathbf{3 b} & -1.89 & -2.71 & -3.03 & -5.86 & -6.08 & -6.12 & 2.83 \\ 3 & \mathbf{4} & -2.16 & -3.60 & -3.84 & -5.77 & -5.91 & -6.16 & 1.93 \\ 4 & \mathbf{5} & -2.23 & -3.55 & -3.78 & -5.66 & -5.77 & -6.09 & 1.88\end{array}$




\section{SYNTHETIC PROCEDURES:}

For the preparation of $o$-phenylenediamine $11,{ }^{3} o$-diamine-benzothiadiazole $12,{ }^{4}$ and $o$-diamine-phenazine $13^{5}$ literature protocols were followed.

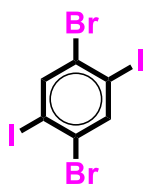

1,4-dibromo-2,5-diiodobenzene 7. A of solution of 1,4-dibromobenzene 6 (15 g, $63.6 \mathrm{mmol})$ and iodine (62 g, 244 mmol, 3.8 equiv) in $120 \mathrm{~mL}$ of concentrated sulfuric acid was stirred at $130{ }^{\circ} \mathrm{C}$ for $16 \mathrm{~h}$. The mixture was poured into ice-water and the precipitate was filtered and washed successively with $10 \%$ aqueous sodium bisulfite, $\mathrm{H}_{2} \mathrm{O}$ and sodium bicarbonate. The mixture was later dissolved up in $\mathrm{CHCl}_{3}(60 \mathrm{~mL})$ and washed with $10 \%$ aqueous sodium bisulfite $(2 \times 30 \mathrm{~mL})$, sodium bicarbonate $(2 \times 30 \mathrm{~mL})$, and $\mathrm{H}_{2} \mathrm{O}(1 \times 30 \mathrm{~mL})$. After the removal of the solvent a white solid $(14 \mathrm{~g}, 80 \%)$ was obtained. The spectroscopic data recorded for this material (vide infra) were in good agreement with those reported in the literature. ${ }^{6}$ ${ }^{1} \mathrm{H}$ NMR $\left(\mathrm{CDCl}_{3}, 400 \mathrm{MHz}\right) \delta: 8.05(\mathrm{~s}, 2 \mathrm{H}) .{ }^{13} \mathrm{C}\left\{{ }^{1} \mathrm{H}\right\} \mathrm{NMR}\left(\mathrm{CDCl}_{3}, 125 \mathrm{MHz}\right) \delta: 142.5,129.4,101.5$.

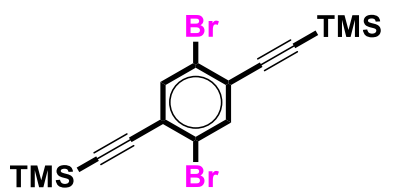

((2,5-dibromo-1,4-phenylene)bis(ethyne-2,1-diyl))bis(trimethylsilane) 8. To mixture of 7 (10 g, $20.5 \mathrm{mmol}$ ), $\mathrm{PPh}_{3}$ (538 mg, $2.05 \mathrm{mmol}, 10 \mathrm{~mol} \%$ ), CuI (781 mg, $4.1 \mathrm{mmol}, 20 \mathrm{~mol} \%$ ) and $\mathrm{PdCl}_{2}\left(\mathrm{PPh}_{3}\right)_{2}(720 \mathrm{mg}, 1.03 \mathrm{mmol}, 5 \mathrm{~mol} \%)$ were added degassed THF $(120 \mathrm{~mL})$ and ${ }^{i} \mathrm{Pr}_{2} \mathrm{NH}(40$ $\mathrm{mL})$ via cannula at $0{ }^{\circ} \mathrm{C}$. Trimethylsilylacetylene $(6.25 \mathrm{~mL}, 45.1 \mathrm{mmol}, 2.2$ equiv) was dropwise added at this temperature and then, the reaction was allowed to warm up to room temperature. After $16 \mathrm{~h}$, the crude reaction was diluted in AcOEt $(150 \mathrm{~mL})$ and poured into an ice-HCl bath $(50 \mathrm{~g}$ and $150 \mathrm{~mL}, 2 \mathrm{M})$. The organic layer was separated and the aqueous layer extracted $(2 \times 75 \mathrm{~mL}, \mathrm{AcOEt})$. The combined organic layers were then dried over anhydrous $\mathrm{Na}_{2} \mathrm{SO}_{4}$ and filtered. After the removal of the solvent a yellowish solid was obtained and after several washings with $\mathrm{MeOH}$ the desired product was isolated as a white solid (5.6 g, $13.1 \mathrm{mmol}, 64 \%)$. The spectroscopic data recorded for this material (vide infra) were in good agreement with those reported in the literature. ${ }^{7}{ }^{1} \mathrm{H} \mathrm{NMR}\left(\mathrm{CDCl}_{3}, 400 \mathrm{MHz}\right) \delta: 7.67(\mathrm{~s}, 2 \mathrm{H}), 0.27(\mathrm{~s}, 18 \mathrm{H}) .{ }^{13} \mathrm{C}\left\{{ }^{1} \mathrm{H}\right\} \mathrm{NMR}\left(\mathrm{CDCl}{ }_{3}, 125 \mathrm{MHz}\right) \delta: 136.5$, $126.6,123.9,103.2,101.5,-0.15$.

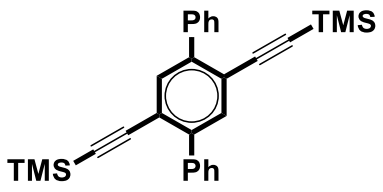

((4,4''-di-tert-butyl-[1,1':4',1"'-terphenyl]-2',5'-diyl)bis(ethyne-2,1-diyl))bis(trimethylsilane) 9a. To a solution of $\mathbf{8}(2.80 \mathrm{~g}, 6.54 \mathrm{mmol})$ and phenylboronic acid (1.83 g, $15 \mathrm{mmol}, 2.3$ equiv) in dry toluene $\left.(150 \mathrm{~mL})\left[\mathrm{PdPPh}_{3}\right)_{4}\right](381 \mathrm{mg}, 0.33 \mathrm{mmol}, 5 \mathrm{~mol} \%)$ was added. After, the mixture was heated to reflux and reacted overnight. The solvent was removed and the yellowish solid was thoroughly washed with $\mathrm{MeOH}$. Then it was dissolved up in hexane:DCM (1:1) and after the removal of the solvent, the solid was washed with $\mathrm{MeOH}$. The titled compound was isolated as a white solid (1.66 g, $3.92 \mathrm{mmol}, 60 \%)$. The spectroscopic data recorded for this material (vide infra) were in good agreement with those reported in the literature. ${ }^{8}{ }^{1} \mathrm{H} \mathrm{NMR}\left(\mathrm{CDCl}_{3}, 400 \mathrm{MHz}\right) \delta: 7.75-7.65$ (m, 6H), 7.51$7.36(\mathrm{~m}, 6 \mathrm{H}), 0.19$ (s, 18H). ${ }^{13} \mathrm{C}\left\{{ }^{1} \mathrm{H}\right\} \mathrm{NMR}\left(\mathrm{CDCl}_{3}, 125 \mathrm{MHz}\right) \delta: 142.8,139.2,134.3,129.4,128.0,127.8,127.6,121.9,104.4,99.6$, -0.21 .

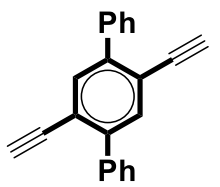

4,4"'-di-tert-butyl-2',5'-diethynyl-1,1':4',1"'-terphenyl 10a. To a solution of 9a (1.66 g, $3.92 \mathrm{mmol})$ in hexane $(40 \mathrm{~mL})$, THF $(20 \mathrm{~mL}), \mathrm{MeOH}(80 \mathrm{~mL})$ and saturated $\mathrm{K}_{2} \mathrm{CO}_{3}(\mathrm{aq}, 8 \mathrm{~mL})$ was added. The mixture was stirred at room temperature for $4 \mathrm{~h}$ and after the removal of the solvent the white solid was washed with $\mathrm{H}_{2} \mathrm{O}$ and $\mathrm{MeOH}$. The titled product was isolated as a white solid (1.09 g, $3.92 \mathrm{mmol}$, quantitative) The spectroscopic data recorded for this material (vide infra) were in good agreement with those reported in the literature. $\left.{ }^{8} \mathrm{H} \mathrm{NMR}_{(\mathrm{CDCl}}, 400 \mathrm{MHz}\right) \delta$ : $7.71-7.57$ $(\mathrm{m}, 6 \mathrm{H}), 7.50-7.37(\mathrm{~m}, 6 \mathrm{H}), 3.14(\mathrm{~s}, 2 \mathrm{H}) .{ }^{13} \mathrm{C}\left\{{ }^{1} \mathrm{H}\right\} \mathrm{NMR}\left(\mathrm{CDCl}_{3}, 125 \mathrm{MHz}\right) \delta: 142.9,138.9,134.9,129.1,128.1,127.9,121.1,82.5$, 81.8 . 


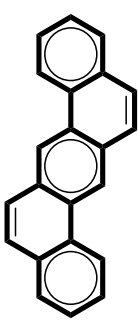

3,10-di-tert-butyldibenzo[a,h]anthracene 1a. After drying $\mathrm{PtCl}_{2}(261 \mathrm{mg}, 0.98 \mathrm{mmol}, 25 \mathrm{~mol} \%)$ under vacuum for $1 \mathrm{~h}$ a solution of $\mathbf{1 0 a}(1.09 \mathrm{~g}, 3.9 \mathrm{mmol})$ in toluene $(50 \mathrm{~mL})$ was added via cannula at room temperature. The mixture was stirred at $110{ }^{\circ} \mathrm{C}$ for $2 \mathrm{~h}$ and filtered through a short plug of Celite ${ }^{\circledR}$ using $\mathrm{CH}_{2} \mathrm{Cl}_{2}$ as eluant. The solvent was removed and the brown solid was successively washed with $\mathrm{MeOH}, \mathrm{EtOH}$ and ${ }^{i} \mathrm{PrOH}$ until no coloration was observed in the washings. The titled product was isolated as a light brown solid (621 mg, $2.22 \mathrm{mmol}, 57 \%)$. The spectroscopic data recorded for this material (vide infra) were in good agreement with those reported in the literature. ${ }^{8} \mathrm{H}$ NMR $\left(\mathrm{CDCl}_{3}, 400 \mathrm{MHz}\right) \delta: 9.15(\mathrm{~s}, 2 \mathrm{H}), 8.79(\mathrm{~d}, 2 \mathrm{H}, J=8.1 \mathrm{~Hz}), 7.96(\mathrm{~d}, 2 \mathrm{H}, J=9.0 \mathrm{~Hz}), 7.92(\mathrm{dd}, 2 \mathrm{H}, J=7.7,1.5 \mathrm{~Hz}), 7.79-7.62(\mathrm{~m}$, $6 \mathrm{H}) .{ }^{13} \mathrm{C}\left\{{ }^{1} \mathrm{H}\right\} \mathrm{NMR}\left(\mathrm{CDCl}_{3}, 125 \mathrm{MHz}\right) \delta: 132.2,131.0,130.5,129.3,128.8,127.6,127.4,127.2,127.0,123.1,122.3$.

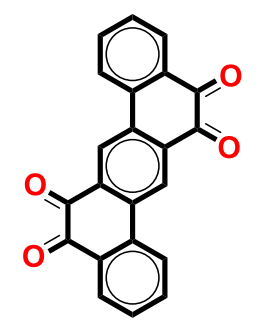

Dibenzo[a,h]anthracene-5,6,12,13-tetraone 2a. To a solution of $1 \mathbf{a}(621 \mathrm{mg}, 2.22 \mathrm{mmol})$ and $\mathrm{RuCl}_{3} \cdot \mathrm{xH}_{2} \mathrm{O}$ (116 mg, $0.56 \mathrm{mmol}, 25 \mathrm{~mol} \%$ ) in $\mathrm{CHCl}_{3}: \mathrm{CH}_{3} \mathrm{CN}: \mathrm{H}_{2} \mathrm{O}(1: 1: 1.2,32 \mathrm{~mL}) \mathrm{NaIO}_{4}(4.27 \mathrm{~g}, 20.0 \mathrm{mmol}, 9$ equiv) was added portionwise. The mixture was stirred at $60{ }^{\circ} \mathrm{C}$ for $18 \mathrm{~h}$ and filtered by suction. Then, the reddish solid was suspended in $\mathrm{AcOH}(6 \mathrm{~mL}), \mathrm{Na}_{2} \mathrm{Cr}_{2} \mathrm{O}_{7}(132 \mathrm{mg}, 0.5 \mathrm{mmol}, 23 \mathrm{~mol} \%$ ) was added and the mixture was stirred at $120{ }^{\circ} \mathrm{C}$ for $30 \mathrm{~min}$. The crude was filtered and thoroughly washed with $\mathrm{MeOH}, \mathrm{CHCl}_{3}$, Acetone and $\mathrm{Et}_{2} \mathrm{O}$ to yield a dark red product $(112 \mathrm{mg}, 0.33 \mathrm{mmol}, 14 \%)$. ATR-IR $\left(\mathrm{cm}^{-1}\right): 1672(\mathrm{C}=\mathrm{O} \mathrm{st})$. Due to the insolubility of the product it was used in the next reaction step without further characterization.

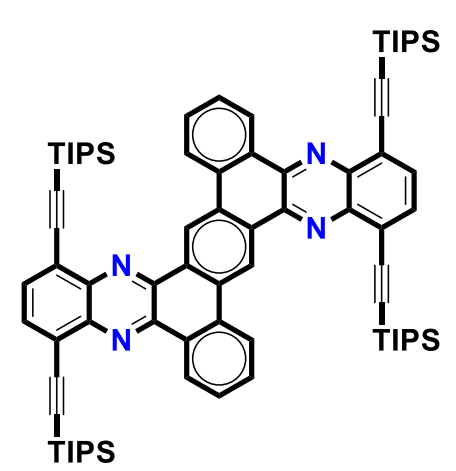

Compound 3a. To a solution of $\mathbf{2 a}(5.3 \mathrm{mg}, 0.015 \mathrm{mmol})$ in $\mathrm{CHCl}_{3}: \mathrm{CH}_{3} \mathrm{COOH}(3: 1,5.0 \mathrm{~mL})$ diamine 11 (17.5 mg, $0.037 \mathrm{mmol}, 2.5$ equiv) was added as a $\mathrm{CHCl}_{3}$ solution $(500 \mu \mathrm{L})$. Then, anhydrous $\mathrm{Na}_{2} \mathrm{SO}_{4}(15 \mathrm{mg})$ was added and the mixture was stirred at $90{ }^{\circ} \mathrm{C}$ for $48 \mathrm{~h}$. After cooling to room temperature saturated $\mathrm{NaHCO}_{3}(\mathrm{aq}, 5 \mathrm{~mL})$ was slowly added and the organic layer was separated. The aqueous layer was extracted with $\mathrm{CHCl}_{3}(3 \times 5 \mathrm{~mL})$ and after the removal of the solvent the solid was filtered by suction and washed with $\mathrm{MeOH}$. After flash chromatography (Petroleum ether: $\mathrm{CHCl}_{3}$ (1:1), Rf: 0.50), the titled product was isolated as a yellow solid (11 mg, $0.0089 \mathrm{mmol}, 59 \%) .{ }^{1} \mathrm{H} \mathrm{NMR}\left(\mathrm{CDCl}_{3}, 400 \mathrm{MHz}\right) \delta: 10.68$ (s, 2H), 9.59 (dd, 2H, $\left.J=8.0,1.4 \mathrm{~Hz}\right)$, $8.97(\mathrm{~d}, 2 \mathrm{H}, J=8.0 \mathrm{~Hz}), 8.06-8.00(\mathrm{~m}, 4 \mathrm{H}), 7.88-7.81(\mathrm{~m}, 2 \mathrm{H}), 7.79-7.76(\mathrm{~m}, 2 \mathrm{H}), 1.38-1.33(\mathrm{~m}$, 42H), 1.33-1.30 (m, 42H). ${ }^{13} \mathrm{C}\left\{{ }^{1} \mathrm{H}\right\} \mathrm{NMR}\left(\mathrm{CDCl}_{3}, 125 \mathrm{MHz}\right) \delta: 143.5,142.9,142.8,142.1,135.1,134.0,132.6,131.82,130.77$, 130.67, 128.4, 127.3, 124.4, 124.2, 124.0, 121.8, 104. 6, 103.8, 100.2, 100.0, 19.1, 19.0, 11.8, 11.7. UV-vis (nm): 283, 290, 331, 345, 416, 440, 456. HRMS (MALDI-TOF) (m/z): calculated for [M+H] $]^{+} \mathrm{C}_{78} \mathrm{H}_{99} \mathrm{~N}_{4} \mathrm{Si}_{4}$ : 1203.6943; found: 1203.6923 .

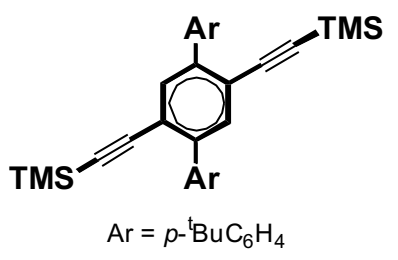

((4,4"'-di-tert-butyl-[1,1':4',1'-terphenyl]-2',5'-diyl)bis(ethyne-2,1-diyl))bis(trimethylsilane)

9b. To a solution of $\mathbf{8}(2.8 \mathrm{~g}, 6.54 \mathrm{mmol})$ and 4-tert-butylphenylboronic acid (2.7 $\mathrm{g}, 15 \mathrm{mmol}, 2.3$ equiv) in dry toluene $\left.(150 \mathrm{~mL})\left[\mathrm{PdPPh}_{3}\right)_{4}\right](381 \mathrm{mg}, 0.33 \mathrm{mmol}, 5 \mathrm{~mol} \%)$ was added. After, the mixture was heated to reflux and reacted overnight. The solvent was removed and the yellowish solid was thoroughly washed with $\mathrm{MeOH}$. Then it was dissolved up in hexane:DCM (1:1) and after the removal of the solvent, the solid was washed with $\mathrm{MeOH}$. The titled compound was isolated as a white solid (2.7 $\mathrm{g}, 5.68 \mathrm{mmol}, 87 \%)$. The spectroscopic data recorded for this material (vide infra) were in good agreement with those reported in the literature. ${ }^{9} \mathrm{H}$ NMR $\left(\mathrm{CDCl}_{3}, 400 \mathrm{MHz}\right) \delta: 7.71-7.56(\mathrm{~m}, 6 \mathrm{H}), 7.51-7.40(\mathrm{~m}, 4 \mathrm{H}), 1.39(\mathrm{~s}, 18 \mathrm{H}), 0.15(\mathrm{~s}, 18 \mathrm{H}) .{ }^{13} \mathrm{C}\left\{{ }^{1} \mathrm{H}\right\} \mathrm{NMR}\left(\mathrm{CDCl}{ }_{3}, 125 \mathrm{MHz}\right) \delta: 151.0$, $142.9,136.7,134.4,129.3,125.2,122.1,105.9,99.7,35.1,31.8,-0.11$.

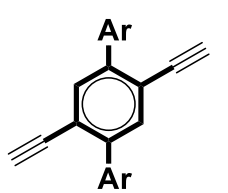

$\mathrm{Ar}=p-{ }^{\mathrm{t}} \mathrm{BuC}_{6} \mathrm{H}_{4}$

4,4"'-di-tert-butyl-2',5'-diethynyl-1,1':4',1"'-terphenyl 10b. To a solution of $9 \mathrm{~b}$ (2.33 g, $4.35 \mathrm{mmol})$ in hexane $(45 \mathrm{~mL})$, THF $(23 \mathrm{~mL}), \mathrm{MeOH}(90 \mathrm{~mL})$ and saturated $\mathrm{K}_{2} \mathrm{CO}_{3}(\mathrm{aq}, 9 \mathrm{~mL})$ was added. The mixture was stirred at room temperature for $4 \mathrm{~h}$ and after the removal of the solvent the white solid was washed with $\mathrm{H}_{2} \mathrm{O}$ and $\mathrm{MeOH}$. The titled product was isolated as a white solid (1.74 g, $4.35 \mathrm{mmol}$, quantitative). The spectroscopic data recorded for this material (vide infra) were in good agreement with those reported in the literature. ${ }^{9}{ }^{1} \mathrm{H} \mathrm{NMR}\left(\mathrm{CDCl}_{3}, 400\right.$ 
$\mathrm{MHz}) \delta: 7.64(\mathrm{~s}, 2 \mathrm{H}), 7.58(\mathrm{~d}, 4 \mathrm{H}, J=8.4 \mathrm{~Hz}), 7.46(\mathrm{~d}, 4 \mathrm{H}, J=8.4 \mathrm{~Hz}), 3.14(\mathrm{~s}, 2 \mathrm{H}), 1.38(\mathrm{~s}, 18 \mathrm{H}) .{ }^{13} \mathrm{C}\left\{{ }^{1} \mathrm{H}\right\} \mathrm{NMR}\left(\mathrm{CDCl}{ }_{3}, 125 \mathrm{MHz}\right)$ $\delta: 151.0,142.5,146.1,135.2,128.9,125.2,125.1,83.0,81.8,34.8,31.5$.

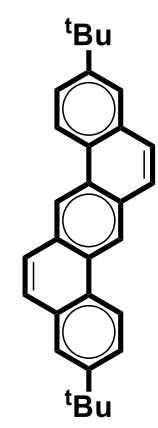

3,10-di-tert-butyldibenzo[a,h]anthracene 1b. After drying $\mathrm{PtCl}_{2}(247 \mathrm{mg}, 0.93 \mathrm{mmol}, 25 \mathrm{~mol} \%)$ under vacuum for $1 \mathrm{~h}$ a solution of $\mathbf{1 0 b}(1.45 \mathrm{mg}, 3.71 \mathrm{mmol})$ in toluene $(50 \mathrm{~mL})$ was added via cannula at room temperature. The mixture was stirred at $110^{\circ} \mathrm{C}$ for $2 \mathrm{~h}$ and filtered through a short plug of celite ${ }^{\circ}$ using $\mathrm{CH}_{2} \mathrm{Cl}_{2}$ as eluant. The solvent was removed and the brown solid was successively washed with $\mathrm{MeOH}$, EtOH and ${ }^{i} \mathrm{PrOH}$ until no coloration was observed in the washings. The titled product was isolated as a light brown solid (906 mg, $2.31 \mathrm{mmol}, 63 \%) .{ }^{1} \mathrm{H} \mathrm{NMR}\left(\mathrm{CDCl}_{3}, 400 \mathrm{MHz}\right)$

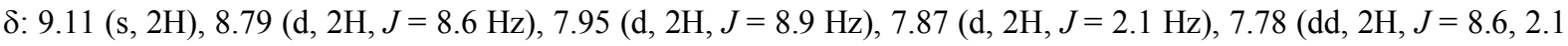
$\mathrm{Hz}), 7.74(\mathrm{~d}, 2 \mathrm{H}, J=8.9 \mathrm{~Hz}), 1.49(\mathrm{~s}, 18 \mathrm{H}) .{ }^{13} \mathrm{C}\left\{{ }^{1} \mathrm{H}\right\} \mathrm{NMR}\left(\mathrm{CDCl}_{3}, 125 \mathrm{MHz}\right) \delta: 150.0,131.9,130.8,129.0,128.2$, 127.6, 127.5, 125.1 124.7, 122.8, 122.0, 35.0, 31.6. HRMS (MALDI-TOF) (m/z): calculated for [M] $]^{+} \mathrm{C}_{30} \mathrm{H}_{30}: 390,2348$; found: 390,2348 .

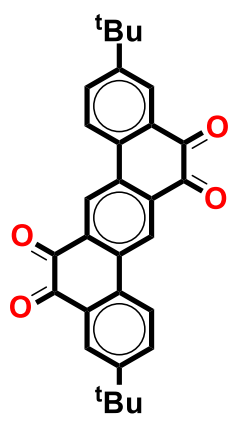

3,10-di-tert-butyldibenzo[a,h]anthracene-5,6,12,13-tetraone $\mathbf{2 b}$. To a solution of $\mathbf{1 b}$ (906 $\mathrm{mg}, 2.3 \mathrm{mmol})$ and $\mathrm{RuCl}_{3} \cdot \mathrm{H}_{2} \mathrm{O}(119 \mathrm{mg}, 0.57 \mathrm{mmol}, 25 \mathrm{~mol} \%)$ in $\mathrm{CHCl}_{3}: \mathrm{CH}_{3} \mathrm{CN}: \mathrm{H}_{2} \mathrm{O}(1: 1: 1.2,32 \mathrm{~mL}) \mathrm{NaIO}_{4}(4.3 \mathrm{~g}, 20.2 \mathrm{mmol}$, 8.8 equiv) was added portionwise. The mixture was stirred at $60{ }^{\circ} \mathrm{C}$ for $18 \mathrm{~h}$ and filtered by suction. Then, the reddish solid was suspended in $\mathrm{AcOH}(6 \mathrm{~mL}), \mathrm{Na}_{2} \mathrm{Cr}_{2} \mathrm{O}_{7}(132 \mathrm{mg}, 0.5 \mathrm{mmol}, 22 \mathrm{~mol} \%$ ) was added and the mixture was stirred at $120^{\circ} \mathrm{C}$ for $30 \mathrm{~min}$. The crude was filtrated through a plug of $\mathrm{SiO}_{2}$ using $\mathrm{CHCl}_{3}$ as eluant. After evaporation of the solvents the solid was purified through flash chromatography $\left(\mathrm{CHCl}_{3}, \mathrm{Rf}: 0.45\right)$. The titled product was isolated as a dark red solid $(170 \mathrm{mg}, 0.38 \mathrm{mmol}, 17 \%) .{ }^{1} \mathrm{H} \mathrm{NMR}\left(\mathrm{CDCl}_{3}, 400 \mathrm{MHz}\right) \delta: 8.74$ $(\mathrm{s}, 2 \mathrm{H}), 8.25(\mathrm{~d}, 2 \mathrm{H}, J=2.2 \mathrm{~Hz}), 8.10(\mathrm{~d}, 2 \mathrm{H}, J=8.4 \mathrm{~Hz}), 7.84(\mathrm{dd}, 2 \mathrm{H}, J=8.4,2.2 \mathrm{~Hz}), 1.40(\mathrm{~s}, 18 \mathrm{H}) .{ }^{13} \mathrm{C}\left\{{ }^{1} \mathrm{H}\right\}$ NMR $\left(\mathrm{CDCl}_{3}, 125 \mathrm{MHz}\right) \delta: 180.4,179.5,154.6,136.1,134.8,134.1,131.9,131.0,127.8,126.1,124.9,35.3,31.1$. ATR-FTIR (cm $\left.{ }^{1}\right)$ : 2968 (C-H st), 1678 (C=O st). HRMS (ESI-TOF) (m/z): calculated for $[\mathrm{M}+\mathrm{H}]^{+}, \mathrm{C}_{30} \mathrm{H}_{27} \mathrm{O}_{4}$ : 451.1904; found: 451.1902.

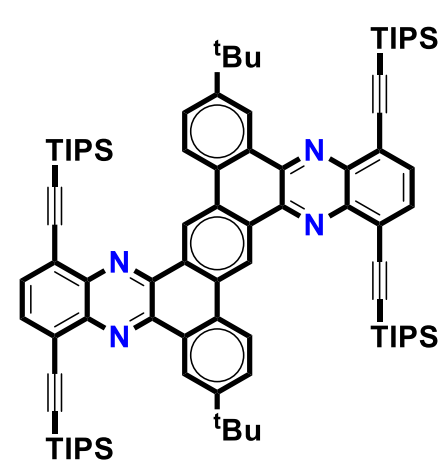

Compound 3b. To a solution of $\mathbf{2 b}(6.7 \mathrm{mg}, 0.015 \mathrm{mmol})$ in $\mathrm{CHCl}_{3}: \mathrm{CH}_{3} \mathrm{COOH}(3: 1,5.0 \mathrm{~mL})$ diamine 11 (17.5 mg, $0.037 \mathrm{mmol}, 2.5$ equiv) was added as a $\mathrm{CHCl}_{3}$ solution $(500 \mu \mathrm{L})$. Then, anhydrous $\mathrm{Na}_{2} \mathrm{SO}_{4}(15 \mathrm{mg})$ was added and the mixture was stirred at $90{ }^{\circ} \mathrm{C}$ for $48 \mathrm{~h}$. After cooling to room temperature saturated $\mathrm{NaHCO}_{3}(\mathrm{aq}, 5 \mathrm{~mL})$ was slowly added and the organic layer was separated. The aqueous layer was extracted with $\mathrm{CHCl}_{3}(3 \times 5 \mathrm{~mL})$ and after the removal of the solvent the solid was filtered by suction and washed with $\mathrm{MeOH}$. After flash chromatography (Petroleum ether: $\mathrm{CHCl}_{3}$ (1:1), Rf: 0.60), the titled product was isolated as a yellow solid (15.1 mg, $0.011 \mathrm{mmol}, 76 \%) .{ }^{1} \mathrm{H}$ NMR $\left(\mathrm{CDCl}_{3}, 400 \mathrm{MHz}\right) \delta: 10.62(\mathrm{~s}, 2 \mathrm{H}), 9.56$ (d, 2H, $\left.J=2.1 \mathrm{~Hz}\right), 8.90$ (d, 2H, $J=8.7 \mathrm{~Hz}), 8.03$ (s, 4H), 7.90 (dd, 2H, $J=8.5,2.2 \mathrm{~Hz}), 1.58$ (s, 18H), 1.39-1.34 (m, 42H),

1.30-1.22 (m, 42H). ${ }^{13} \mathrm{C}\left\{{ }^{1} \mathrm{H}\right\}$ NMR $\left(\mathrm{CDCl}_{3}, 125 \mathrm{MHz}\right) \delta: 151.7,144.0,143.2,142.2,142,135.2,134.7,131.6,131.5,130.4,130.2$, 128.3, 124.4, 124.3, 123.9, 123.4, 121.5, 104. 6, 104.5, 100.1, 100.0, 35.3, 31.6. UV-vis (nm): 283, 292, 350, 337, 416, 438, 472. HRMS (MALDI-TOF) (m/z): calculated for [M+H] ${ }^{+}, \mathrm{C}_{86} \mathrm{H}_{115} \mathrm{~N}_{4} \mathrm{Si}_{4}: 1315.8195$; found: 1315.8206. 


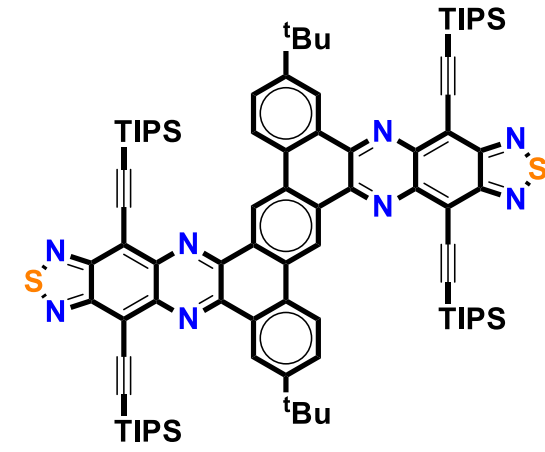

Compound 4. To a solution of $\mathbf{2 b}(50 \mathrm{mg}, 0.11 \mathrm{mmol})$ in $\mathrm{CHCl}_{3}: \mathrm{CH}_{3} \mathrm{COOH}(3: 1,15$ $\mathrm{mL}$ ) diamine 12 (146.2 $\mathrm{mg}, 0.277 \mathrm{mmol}, 2.5$ equiv) was added as a $\mathrm{CHCl}_{3}$ solution (1.5 $\mathrm{mL})$. Then, anhydrous $\mathrm{Na}_{2} \mathrm{SO}_{4}(225 \mathrm{mg})$ was added and the mixture was stirred at $90{ }^{\circ} \mathrm{C}$ for $48 \mathrm{~h}$. After cooling to room temperature saturated $\mathrm{NaHCO}_{3}(\mathrm{aq}, 15 \mathrm{~mL}$ ) was slowly added and the organic layer was separated. The aqueous layer was extracted with $\mathrm{CHCl}_{3}$ $(3 \times 15 \mathrm{~mL})$ and after the removal of the solvent the solid was purified through flash chromatography (Petroleum ether: $\left.\mathrm{CHCl}_{3}(1: 1), \mathrm{Rf}: 0.50\right)$. The titled product was isolated as a red solid (37 mg, $0.024 \mathrm{mmol}, 22 \%) .{ }^{1} \mathrm{H} \mathrm{NMR}\left(\mathrm{CDCl}_{3}, 400 \mathrm{MHz}\right) \delta: 10.49(\mathrm{~s}, 2 \mathrm{H})$, $9.53(\mathrm{~d}, 2 \mathrm{H}, J=2.2 \mathrm{~Hz}), 8.81(\mathrm{~d}, 2 \mathrm{H}, J=8.5 \mathrm{~Hz}), 7.92(\mathrm{dd}, 2 \mathrm{H}, J=8.5,2.2 \mathrm{~Hz}), 1.59$ (s,

$18 \mathrm{H},), 1.47-1.39(\mathrm{~m}, 42 \mathrm{H}), 1.38-1.28(\mathrm{~m}, 42 \mathrm{H}) .{ }^{13} \mathrm{C}\left\{{ }^{1} \mathrm{H}\right\} \mathrm{NMR}\left(\mathrm{CDCl}_{3}, 125 \mathrm{MHz}\right) \delta: 155.7,155.4,152.4,146.1,145.4,141.70$, $141.65,132.5,132.3,130.9,130.1,129.4,124.2,124.1,122.5,114.6,114.5,110.5,110.4,102.3,102.0,35.3,31.6,19.21,19.16$, 12.0, 11.8. UV-vis (nm): 285, 292, 305, 321, 355, 368, 451, 477, 496, 527, 573, 620. HRMS (MALDI-TOF) (m/z): calculated for $[\mathrm{M}+\mathrm{Ag}]^{+}, \mathrm{C}_{86} \mathrm{H}_{110} \mathrm{~N}_{8} \mathrm{~S}_{2} \mathrm{Si}_{4} \mathrm{Ag}: 1537,6423$; found: 1537.6513 .

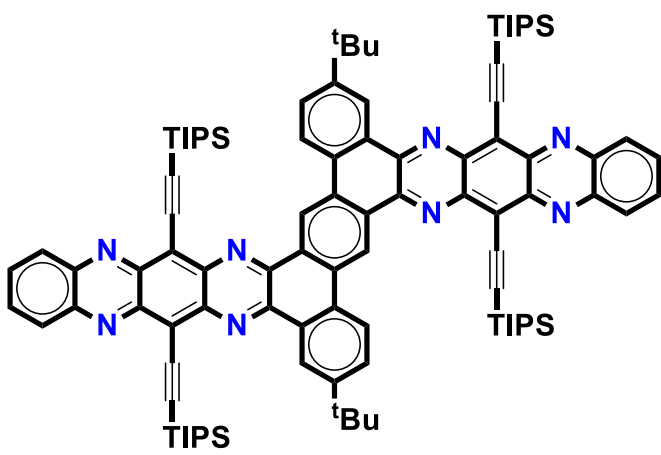

Compound 5. To a solution of $\mathbf{2 b}(20 \mathrm{mg}, 0.044 \mathrm{mmol})$ in $\mathrm{CHCl}_{3}: \mathrm{CH}_{3} \mathrm{COOH}$ (3:1, $6 \mathrm{~mL})$ diamine 13 (62.8 $\mathrm{mg}, 0.093 \mathrm{mmol}, 2.1$ equiv) was added as a $\mathrm{CHCl}_{3}$ solution $(2 \mathrm{~mL})$. Then, anhydrous $\mathrm{Na}_{2} \mathrm{SO}_{4}(150 \mathrm{mg})$ was added and the mixture was stirred at $90{ }^{\circ} \mathrm{C}$ for $48 \mathrm{~h}$. After cooling to room temperature saturated $\mathrm{NaHCO}_{3}(\mathrm{aq}, 6 \mathrm{~mL}$ ) was slowly added and the organic layer was separated. The aqueous layer was extracted with $\mathrm{CHCl}_{3}(3 \times 15 \mathrm{~mL})$ and after the removal of the solvent the solid was purified through flash chromatography (Petroleum ether:AcOEt (98:2), Rf: 0.75). The titled product was isolated as a purple solid (25 mg, $0.017 \mathrm{mmol}, 37 \%) .{ }^{1} \mathrm{H} \mathrm{NMR}\left(\mathrm{CDCl}_{3}, 400 \mathrm{MHz}\right) \delta: 10.65$ (s, 2H), 9.67

(d, 2H, $J=2.2 \mathrm{~Hz}), 8.92(\mathrm{~d}, 2 \mathrm{H}, J=8.6 \mathrm{~Hz}), 8.41-8.30(\mathrm{~m}, 4 \mathrm{H}), 8.01(\mathrm{dd}, 2 \mathrm{H}, J=8.6,2.2 \mathrm{~Hz}), 7.98-7.87$ (m, 4H), 1.66 (s, $18 \mathrm{H}$,$) ,$ 1.58-1.53 (m, 42H), 1.50-1.44 (m, 42H). ${ }^{13} \mathrm{C}\left\{{ }^{1} \mathrm{H}\right\}$ NMR $\left(\mathrm{CDCl}_{3}, 125 \mathrm{MHz}\right) \delta: 152.1,146.1,145.3,145.01,144.96,143.6,143.4$, $141.9,141.8,132.3,131.74,131.71,130.8,130.33,130.30,130.1,129.3,124.2,124.0,122.54,122.52,122.5,111.2,111.1,103.1$, 102.9, 35.2, 31.5, 19.20, 19.16, 12.0, 11.8. UV-vis (nm): 283, 297, 309, 330, 361, 377, 445, 477, 505, 528, 608, 659. HRMS (MALDITOF) (m/z): calculated for $[\mathrm{M}+\mathrm{Ag}]^{+}, \mathrm{C}_{98} \mathrm{H}_{118} \mathrm{~N}_{8} \mathrm{Si}_{4} \mathrm{Ag}$ : 1625,7606 ; found: 1625,7564 . 


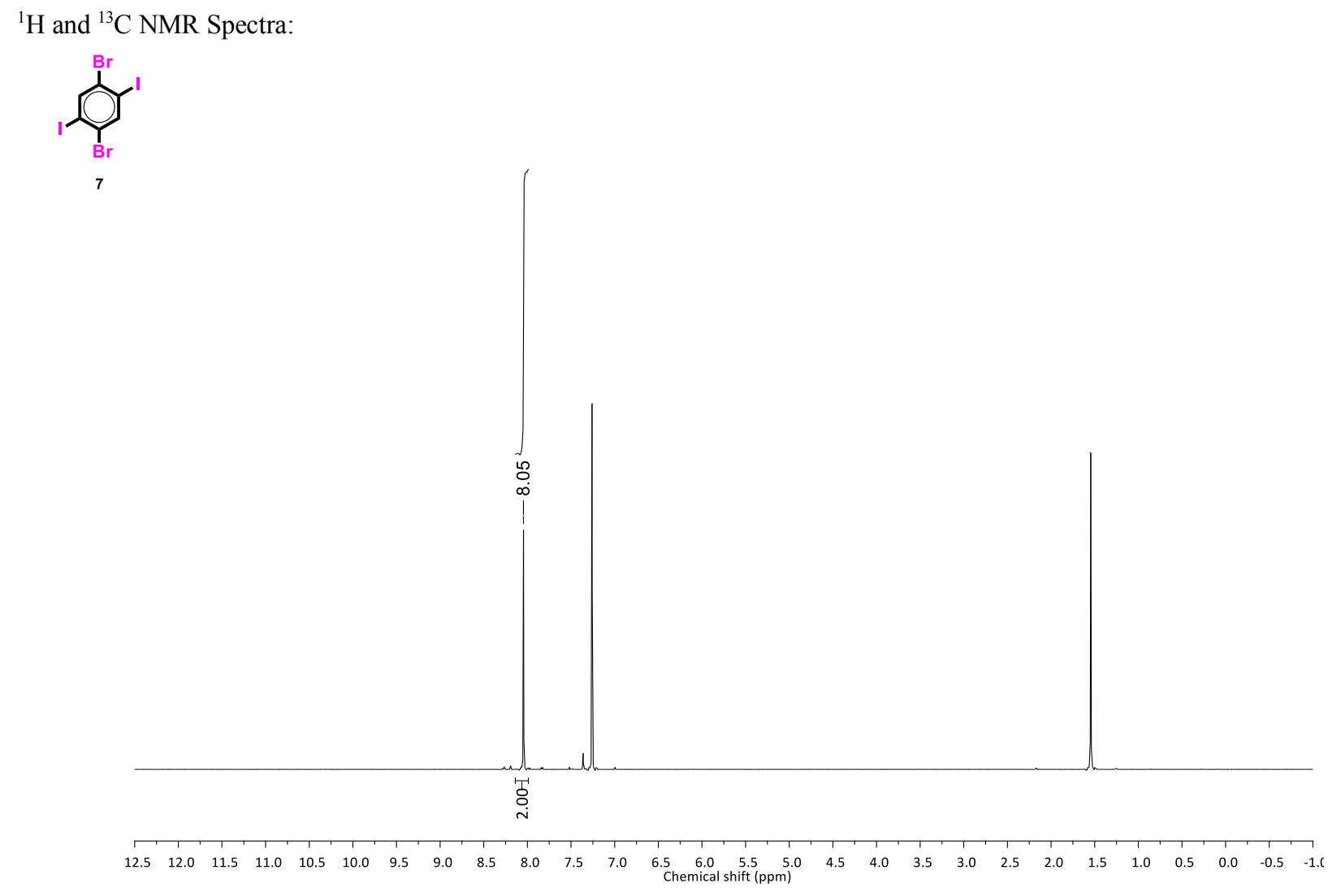

Figure S5. ${ }^{1} \mathrm{H}-\mathrm{NMR}$ of product 7 in $\mathrm{CDCl}_{3}(400 \mathrm{MHz})$.

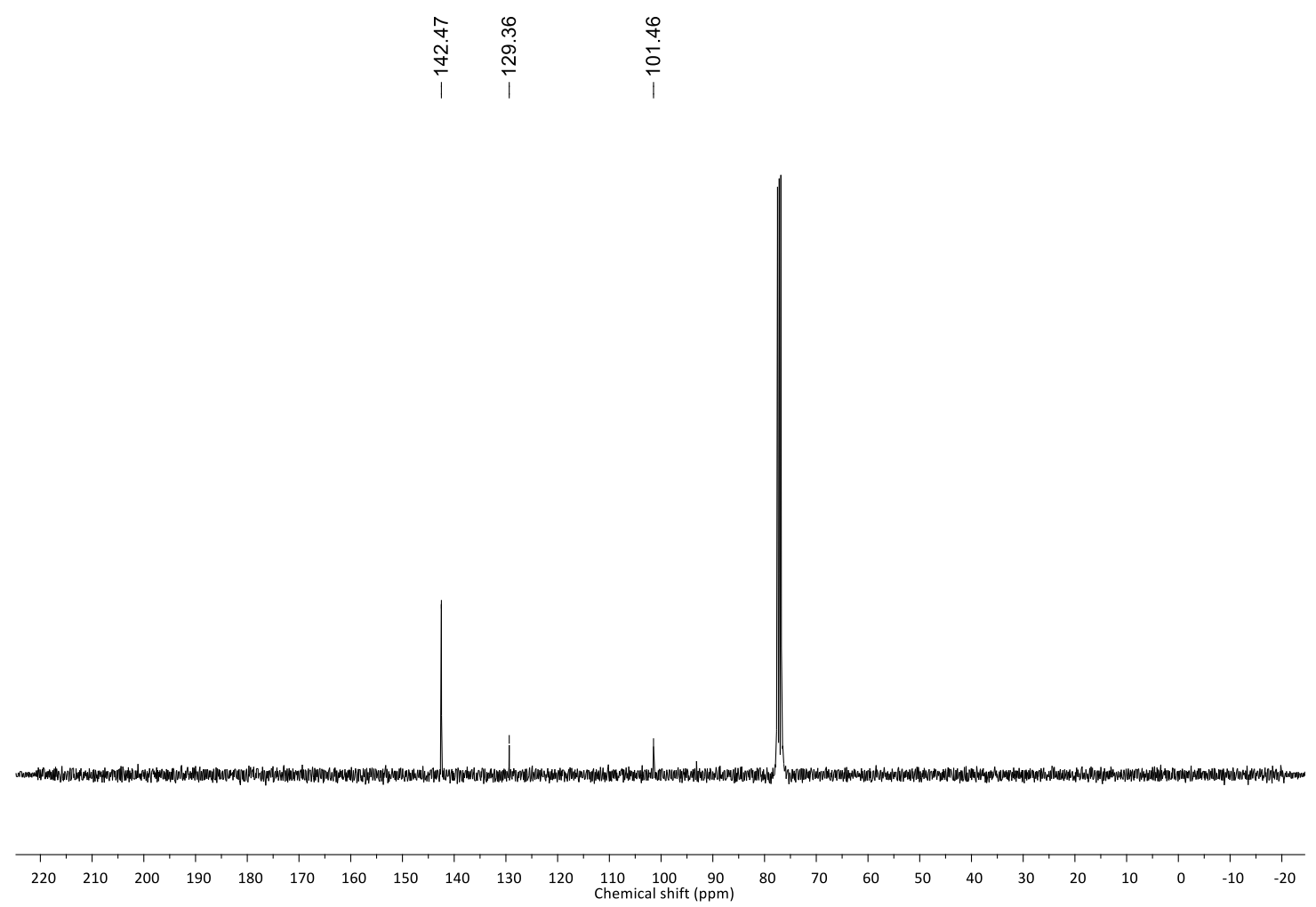

Figure S6. ${ }^{13} \mathrm{C}-\mathrm{NMR}$ of product 7 in $\mathrm{CDCl}_{3}(125 \mathrm{MHz})$. 

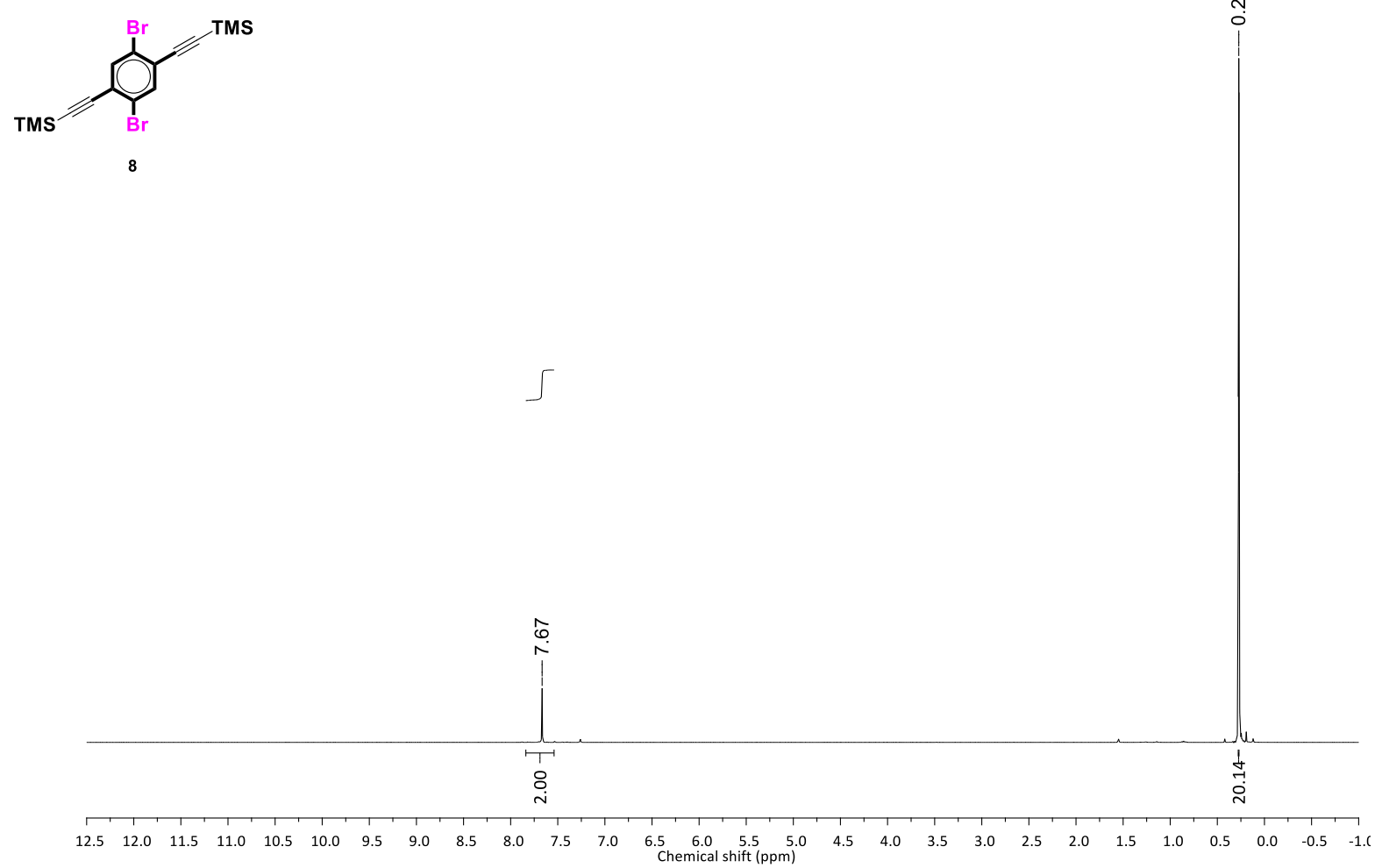

Figure S7. ${ }^{1} \mathrm{H}-\mathrm{NMR}$ of product 8 in $\mathrm{CDCl}_{3}(400 \mathrm{MHz})$.

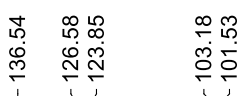

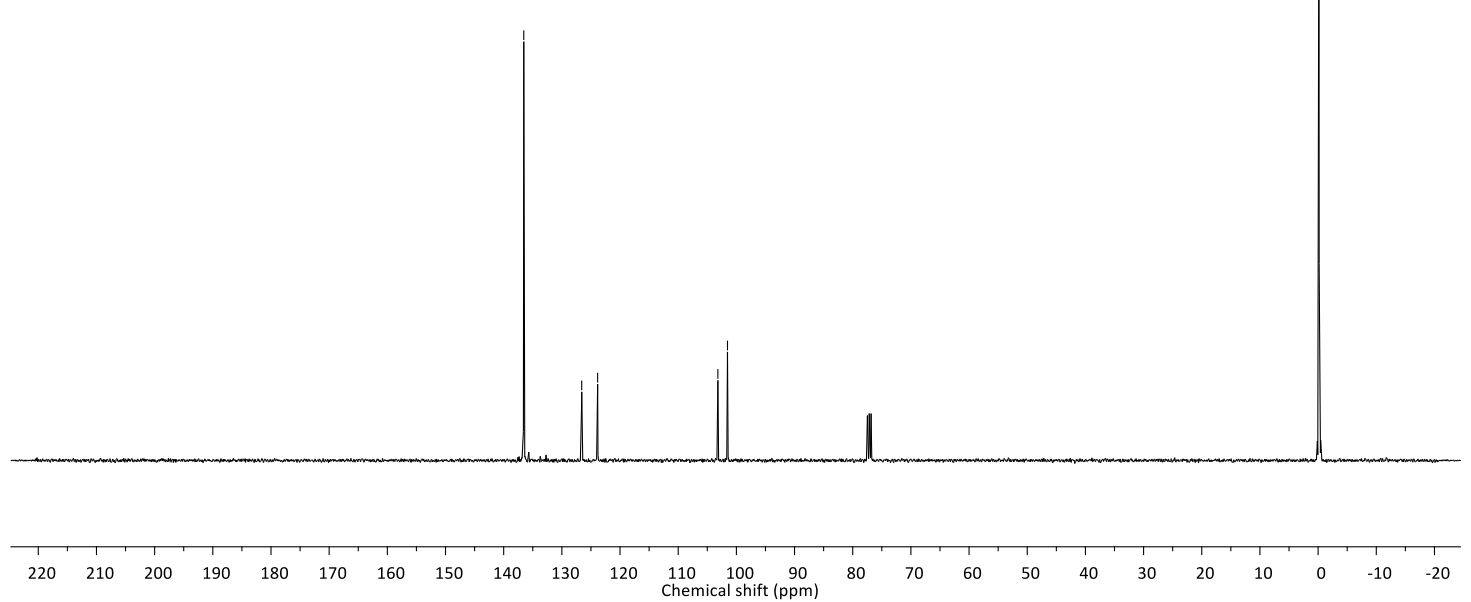

Figure S8. ${ }^{13} \mathrm{C}-\mathrm{NMR}$ of product $\mathbf{8}$ in $\mathrm{CDCl}_{3}(125 \mathrm{MHz})$. 


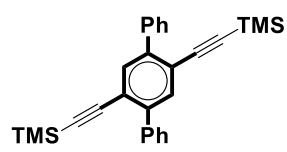

9a

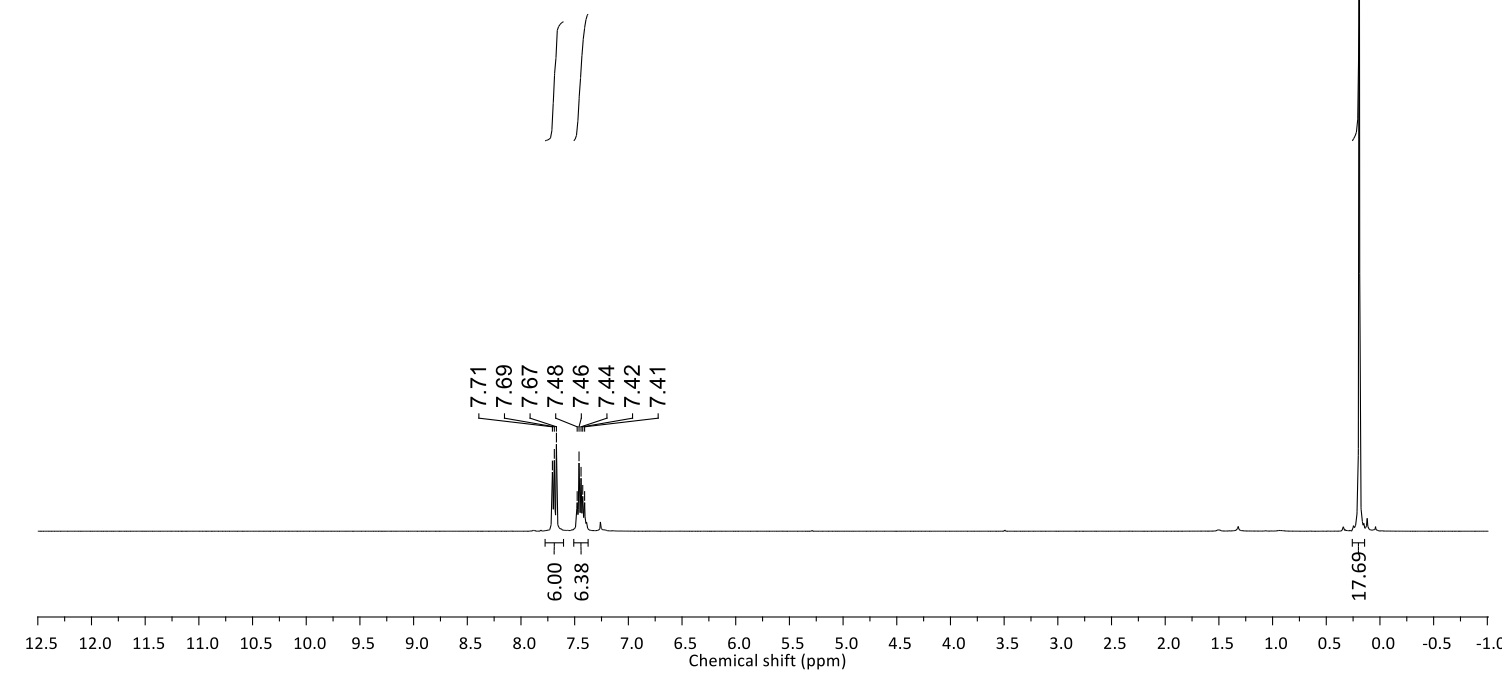

Figure S9. ${ }^{1} \mathrm{H}-\mathrm{NMR}$ of product $9 \mathrm{a}$ in $\mathrm{CDCl}_{3}(400 \mathrm{MHz})$.
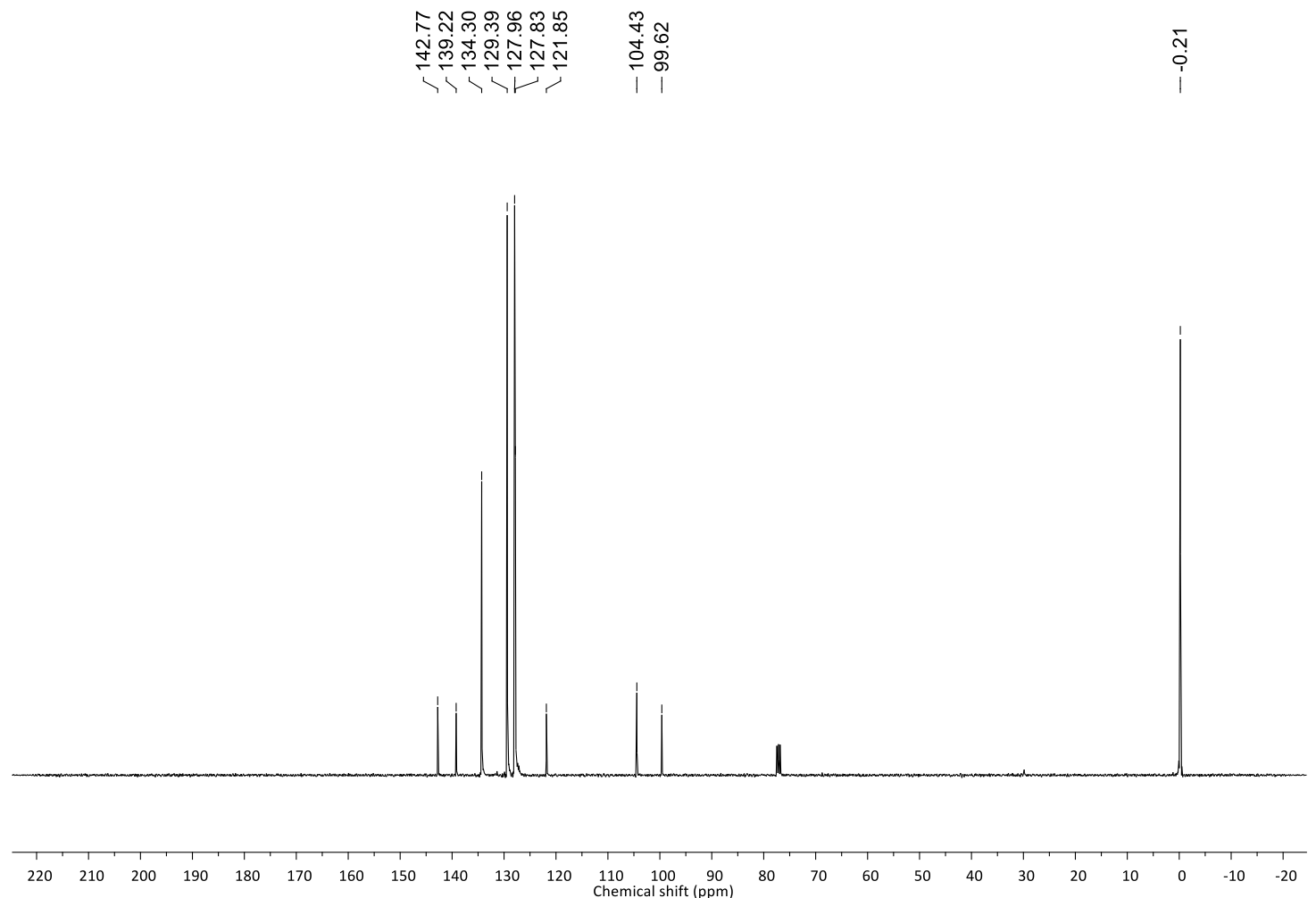

Figure S10. ${ }^{13} \mathrm{C}-\mathrm{NMR}$ of product $9 \mathrm{a}$ in $\mathrm{CDCl}_{3}(125 \mathrm{MHz})$. 

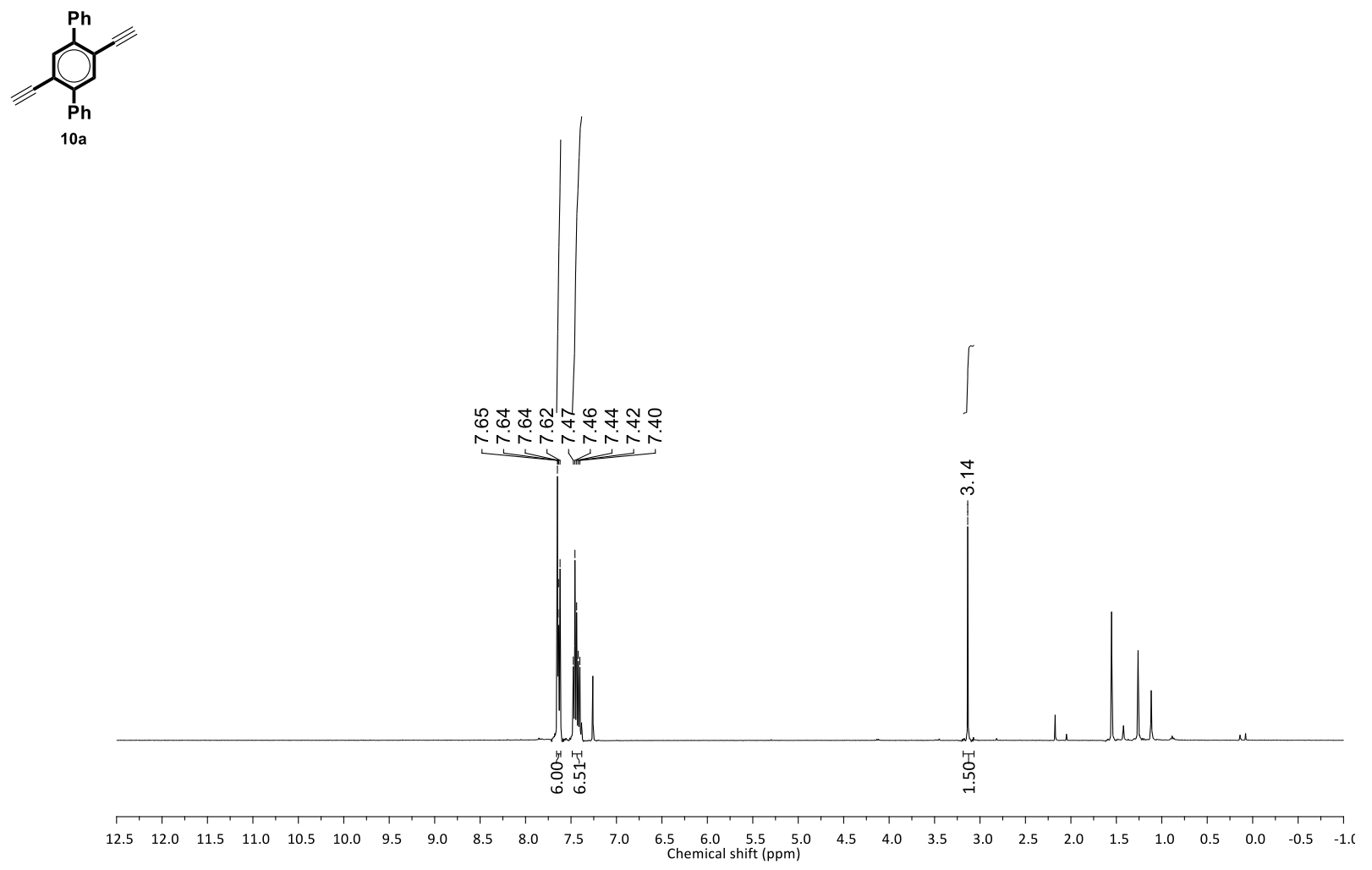

Figure S11. ${ }^{1} \mathrm{H}-\mathrm{NMR}$ of product $\mathbf{1 0 a}$ in $\mathrm{CDCl}_{3}(400 \mathrm{MHz})$.
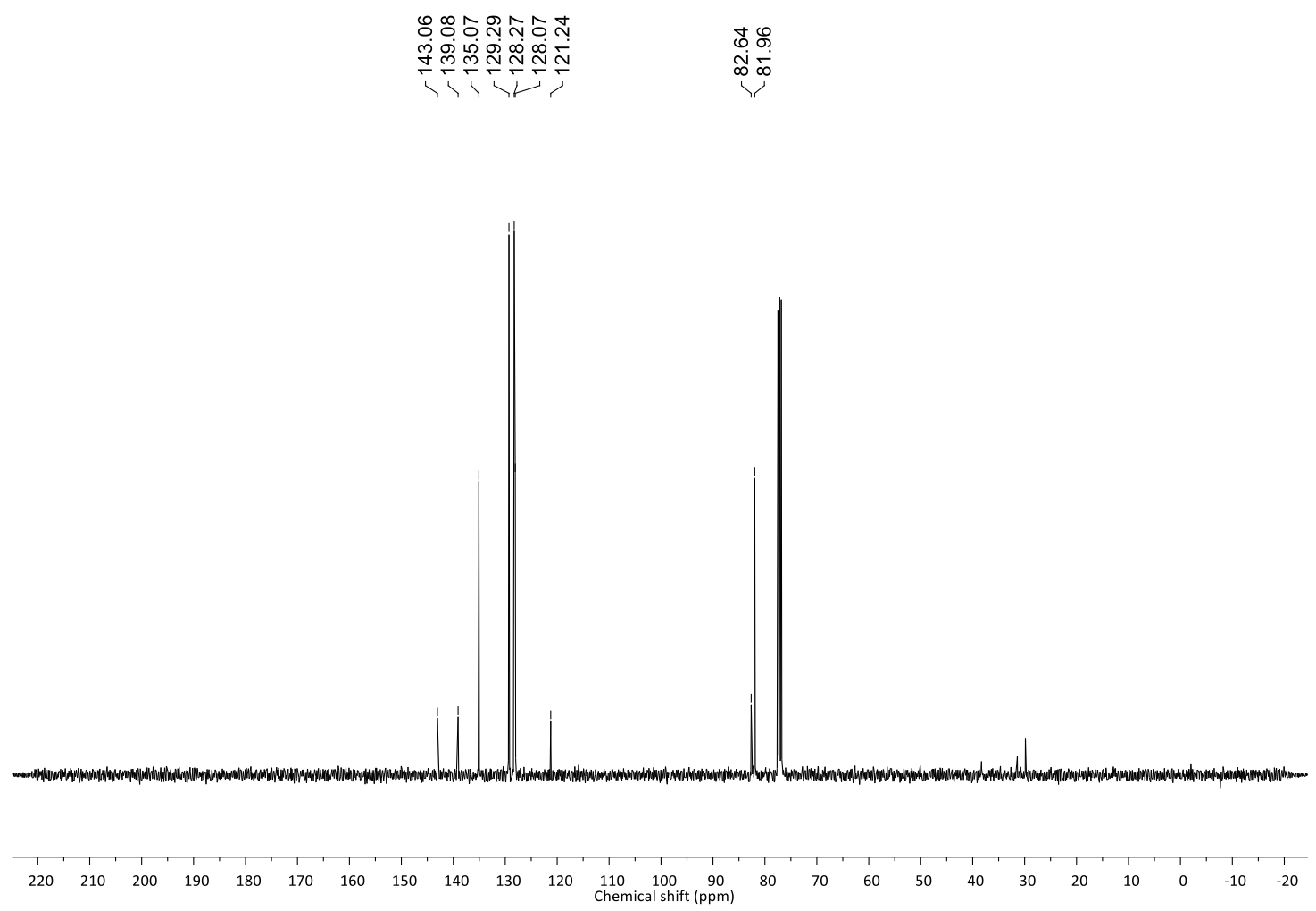

Figure S12. ${ }^{13} \mathrm{C}-\mathrm{NMR}$ of product 10a in $\mathrm{CDCl}_{3}(125 \mathrm{MHz})$. 

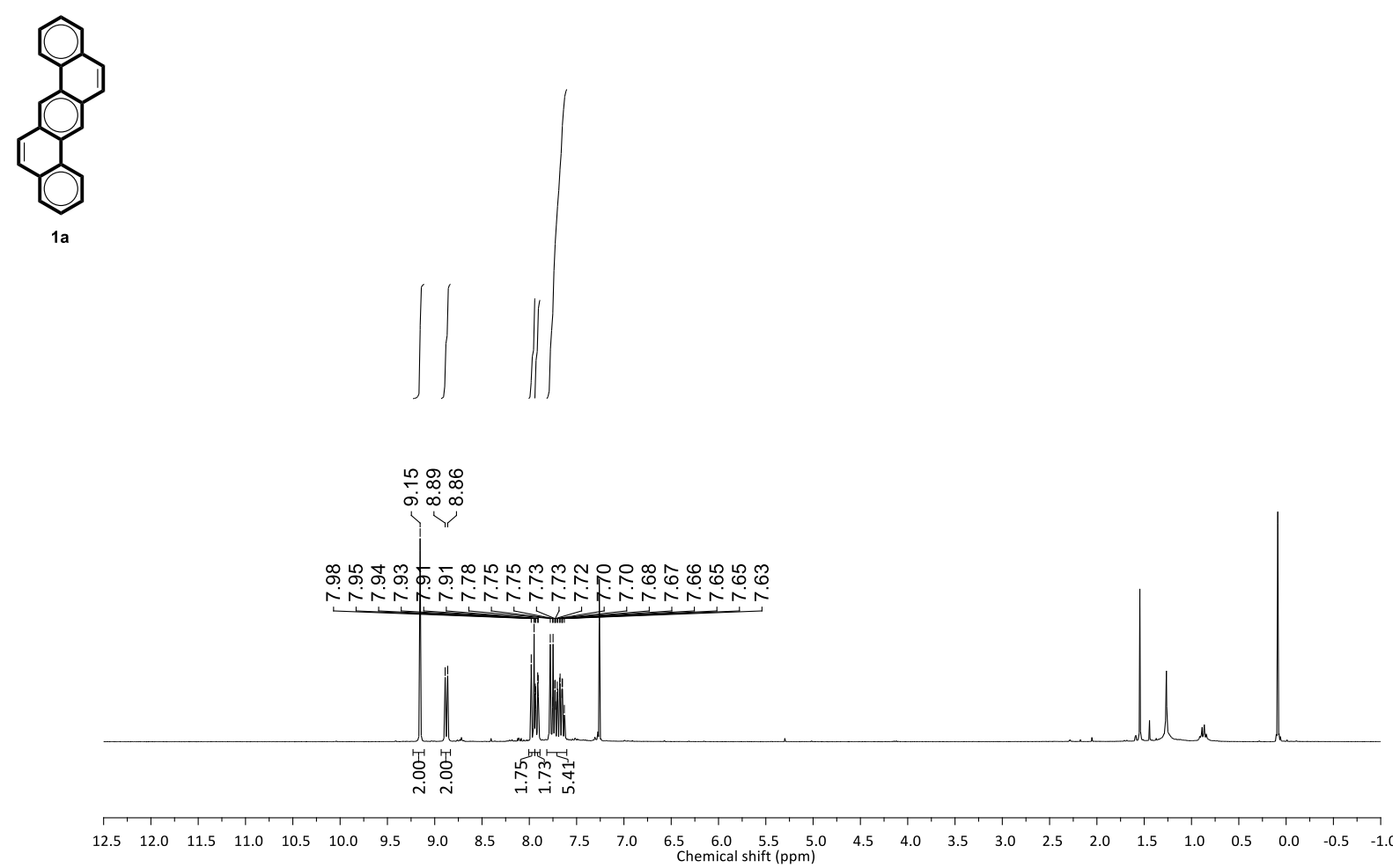

Figure S13. ${ }^{1} \mathrm{H}-\mathrm{NMR}$ of product $1 \mathrm{a}$ in $\mathrm{CDCl}_{3}(400 \mathrm{MHz})$.

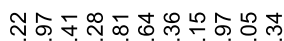

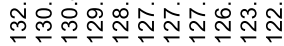
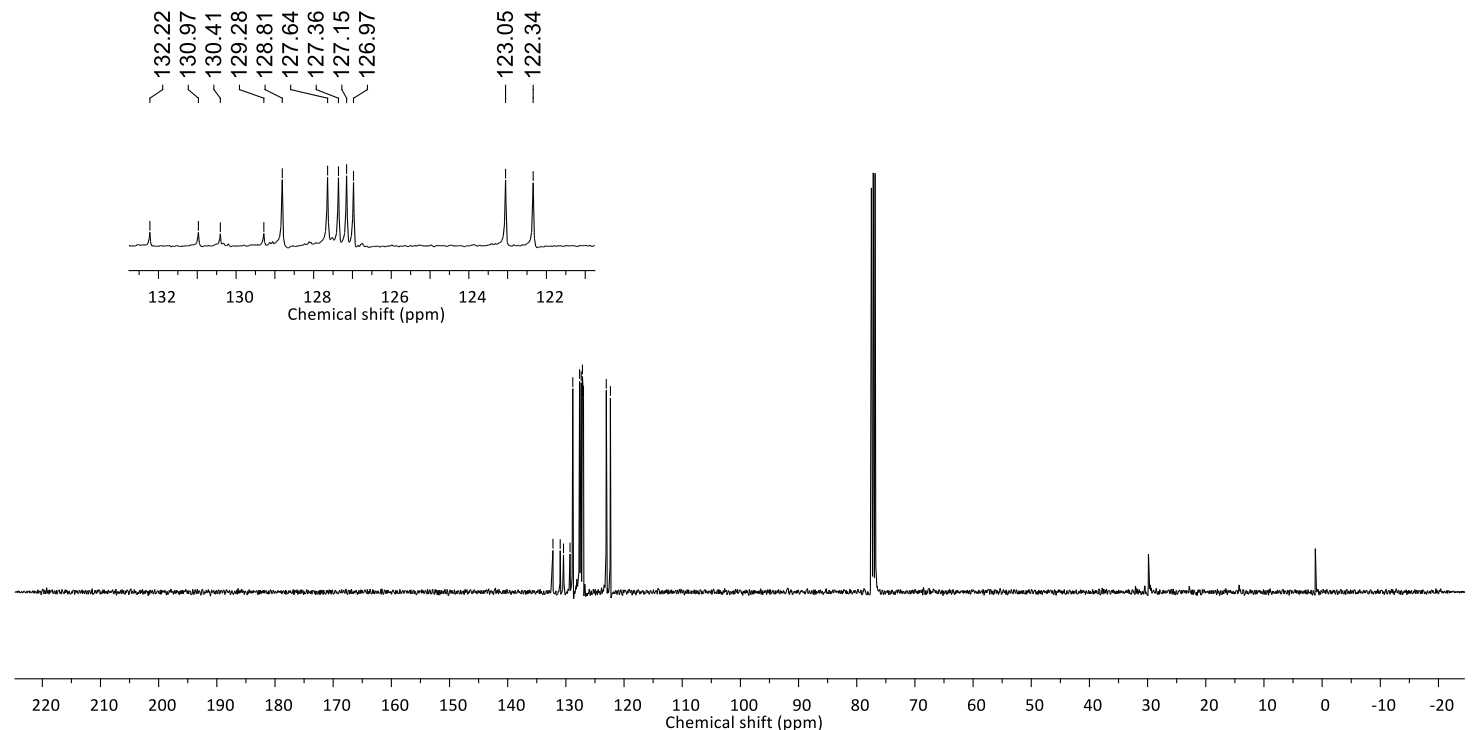

Figure S14. ${ }^{13} \mathrm{C}-\mathrm{NMR}$ of product $1 \mathrm{a}$ in $\mathrm{CDCl}_{3}(125 \mathrm{MHz})$. 

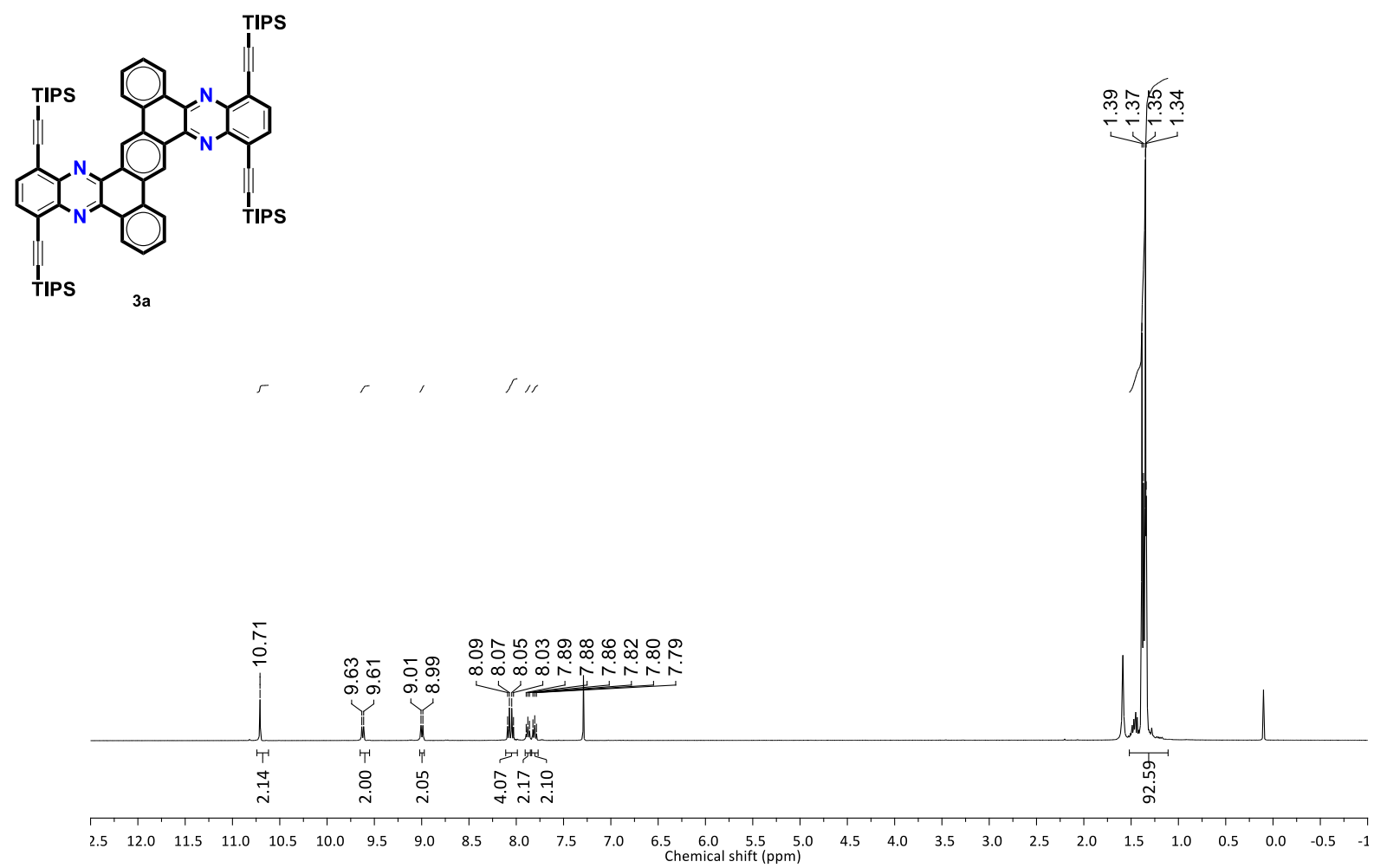

Figure S15. ${ }^{1} \mathrm{H}-\mathrm{NMR}$ of product 3a in $\mathrm{CDCl}_{3}(400 \mathrm{MHz})$.

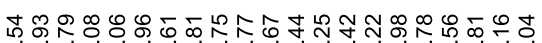

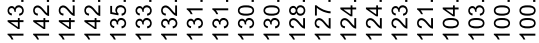

ำ

rththththtrthth

官宁

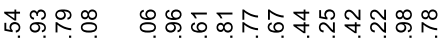

守寺寺寺

垈

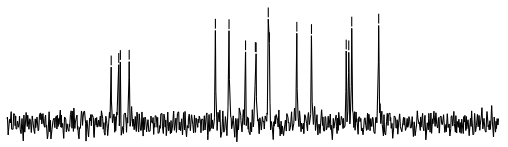

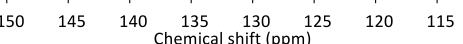

IIIII |

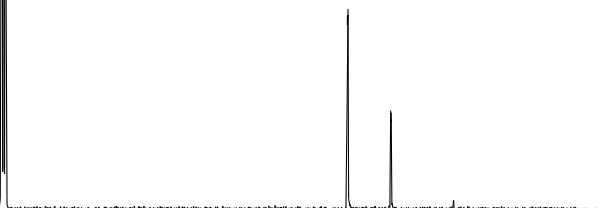

$\begin{array}{lllllllllllllllllllllllll}220 & 210 & 200 & 190 & 180 & 170 & 160 & 150 & 140 & 130 & 120 & \begin{array}{c}110 \\ \text { Chemical shift }(\mathrm{ppm})\end{array} & 80 & 70 & 60 & 50 & 40 & 30 & 20 & 10 & 0 & -10 & -20\end{array}$

Figure S16. ${ }^{13} \mathrm{C}-\mathrm{NMR}$ of product 3a in $\mathrm{CDCl}_{3}(125 \mathrm{MHz})$. 


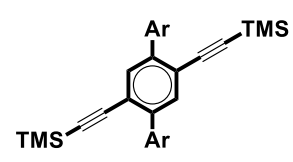

9b, $\mathrm{Ar}=p-{ }^{\mathrm{t}} \mathrm{BuC}_{6} \mathrm{H}_{4}$

$$
\int
$$

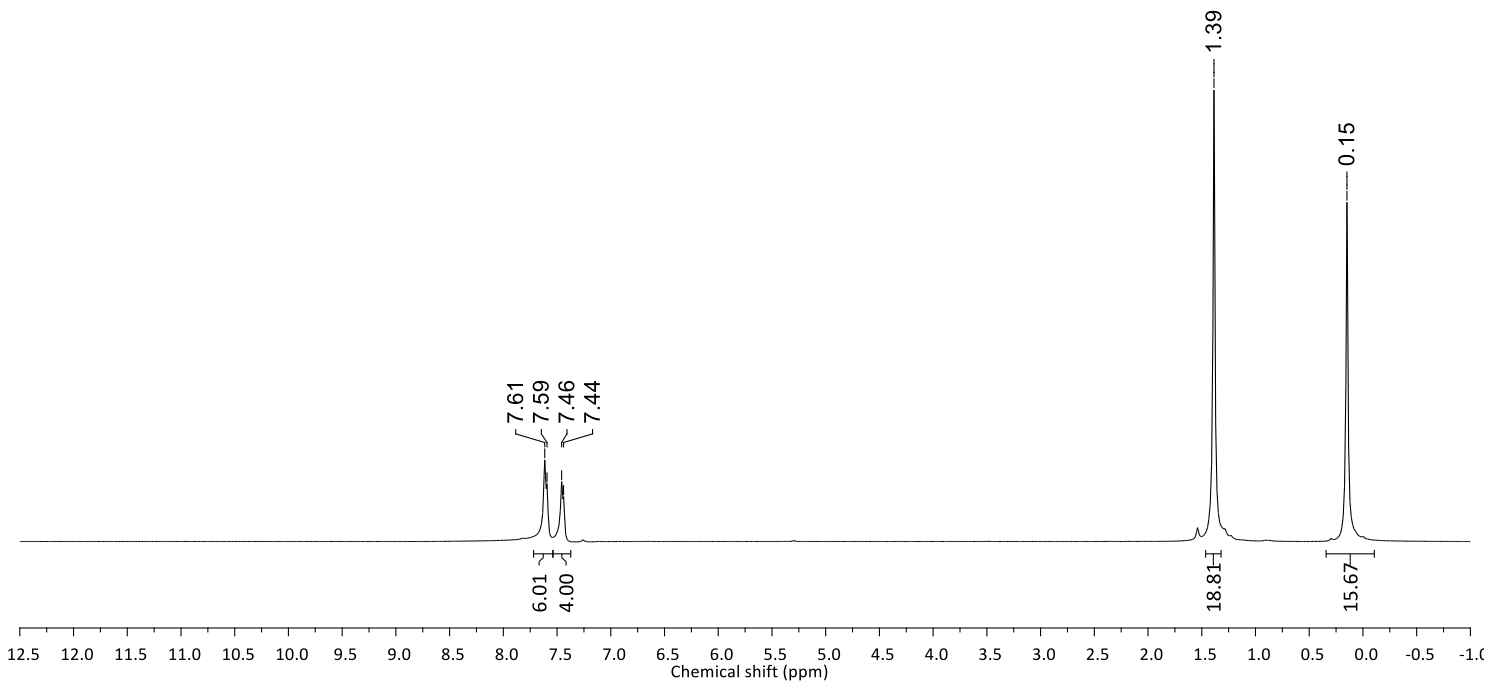

Figure S17. ${ }^{13} \mathrm{C}-\mathrm{NMR}$ of product $9 \mathrm{~b}$ in $\mathrm{CDCl}_{3}(400 \mathrm{MHz})$.

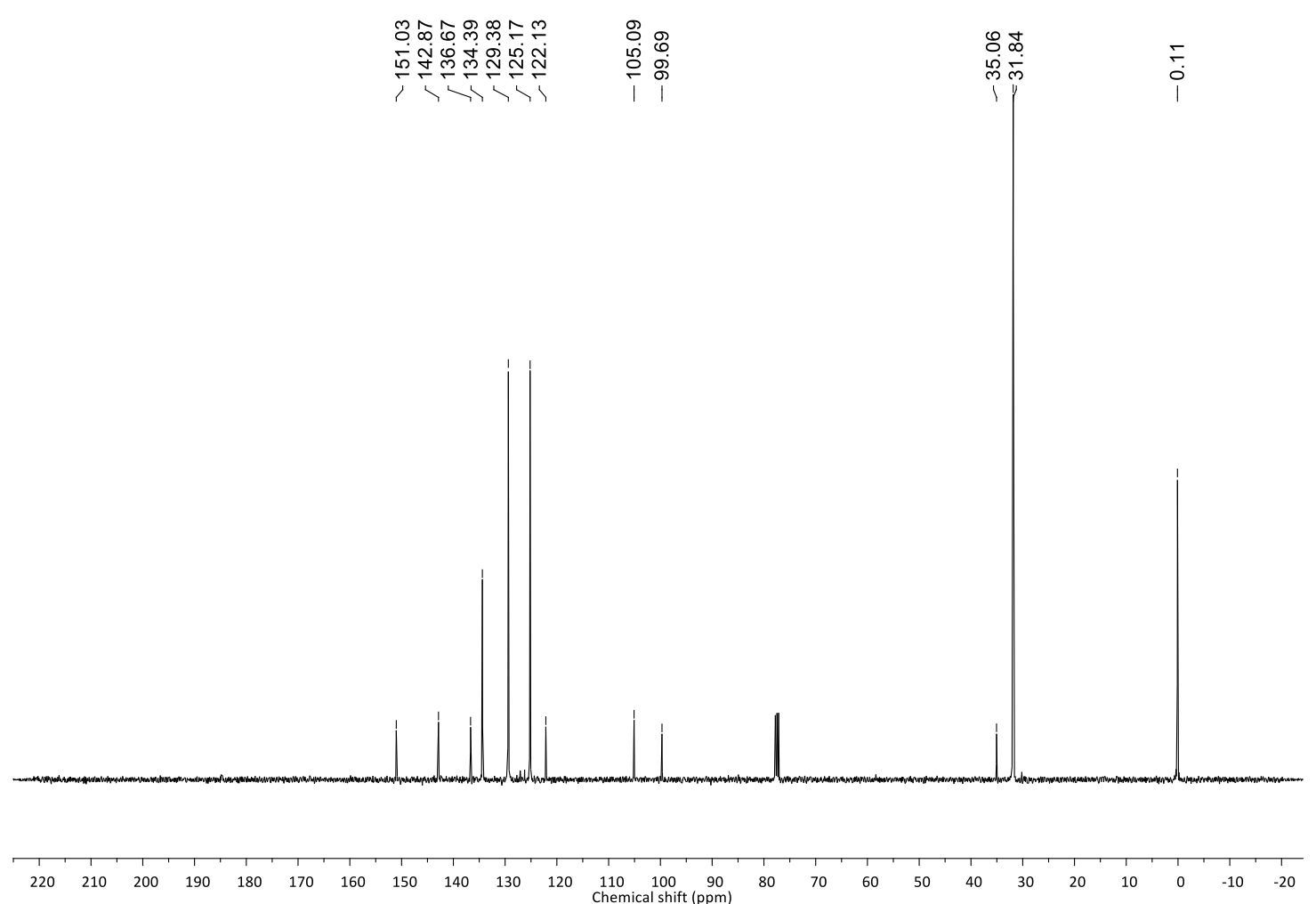

Figure S18. ${ }^{13} \mathrm{C}-\mathrm{NMR}$ of product $\mathbf{9 b}$ in $\mathrm{CDCl}_{3}(125 \mathrm{MHz})$. 


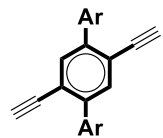

10b, $\mathrm{Ar}=p-{ }^{\mathrm{t}} \mathrm{BuC}_{6} \mathrm{H}_{4}$

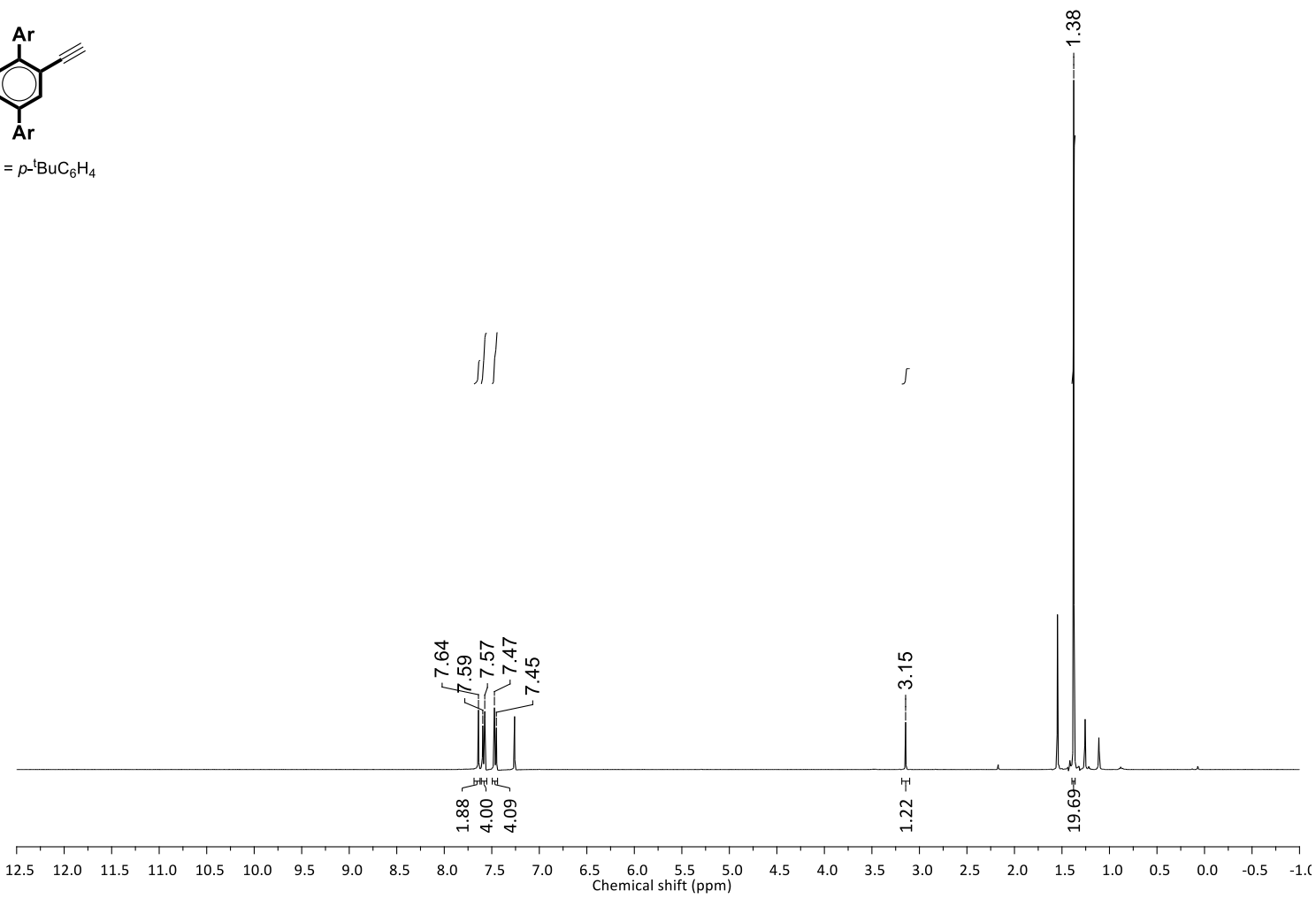

Figure S19. ${ }^{13} \mathrm{C}-\mathrm{NMR}$ of product $\mathbf{1 0 b}$ in $\mathrm{CDCl}_{3}(400 \mathrm{MHz})$.

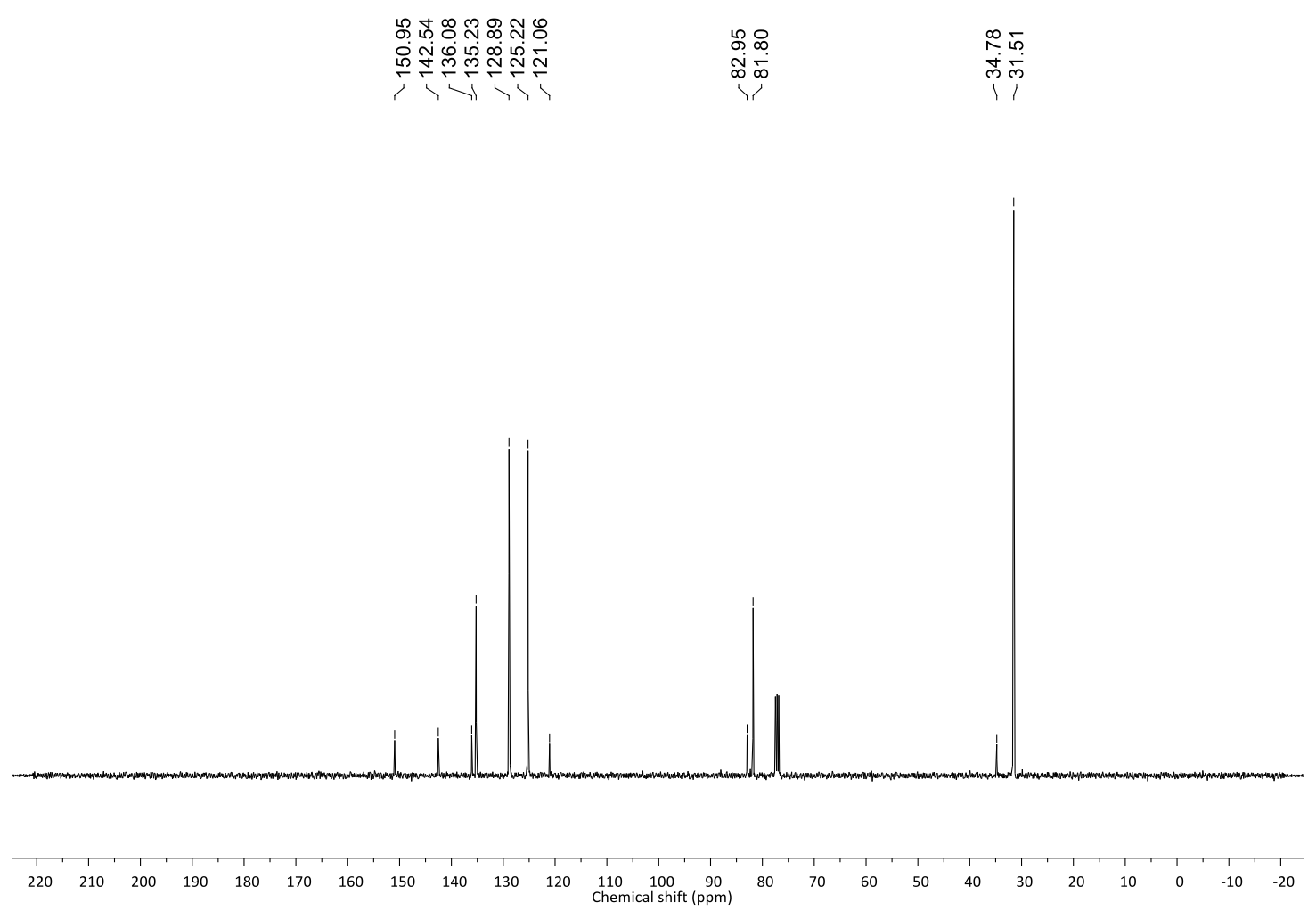

Figure S20. ${ }^{13} \mathrm{C}-\mathrm{NMR}$ of product $\mathbf{1 0 b}$ in $\mathrm{CDCl}_{3}(125 \mathrm{MHz})$. 

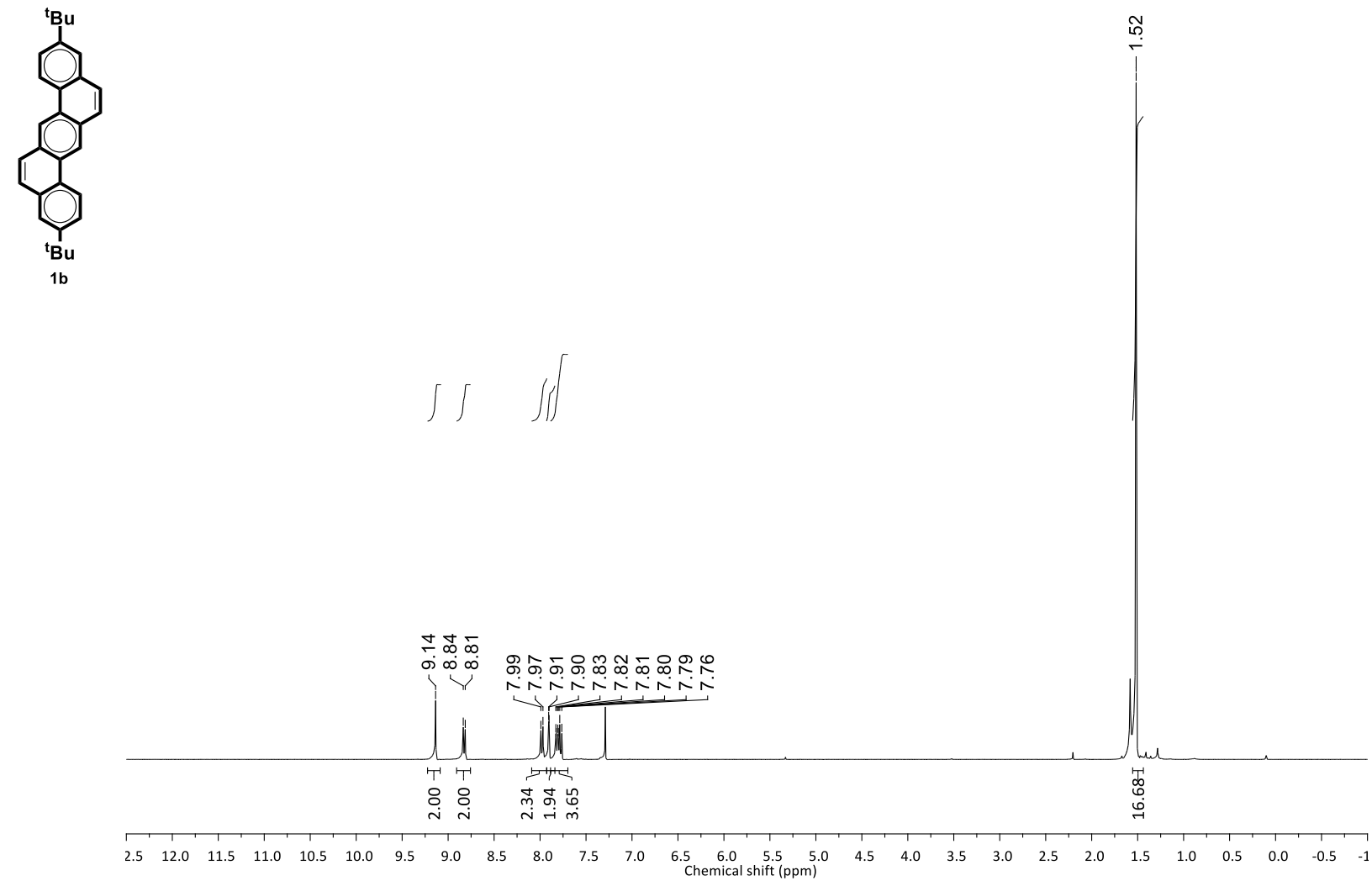

Figure S21. ${ }^{1} \mathrm{H}-\mathrm{NMR}$ of product $\mathbf{1 b}$ in $\mathrm{CDCl}_{3}(400 \mathrm{MHz})$.

శొం

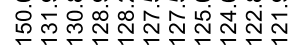

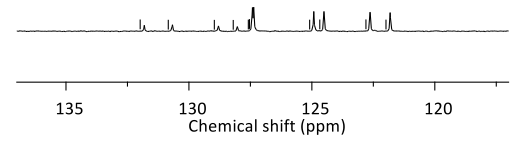

U. Wแ-U

Figure S22. ${ }^{13} \mathrm{C}-\mathrm{NMR}$ of product $\mathbf{1 b}$ in $\mathrm{CDCl}_{3}(125 \mathrm{MHz})$. 

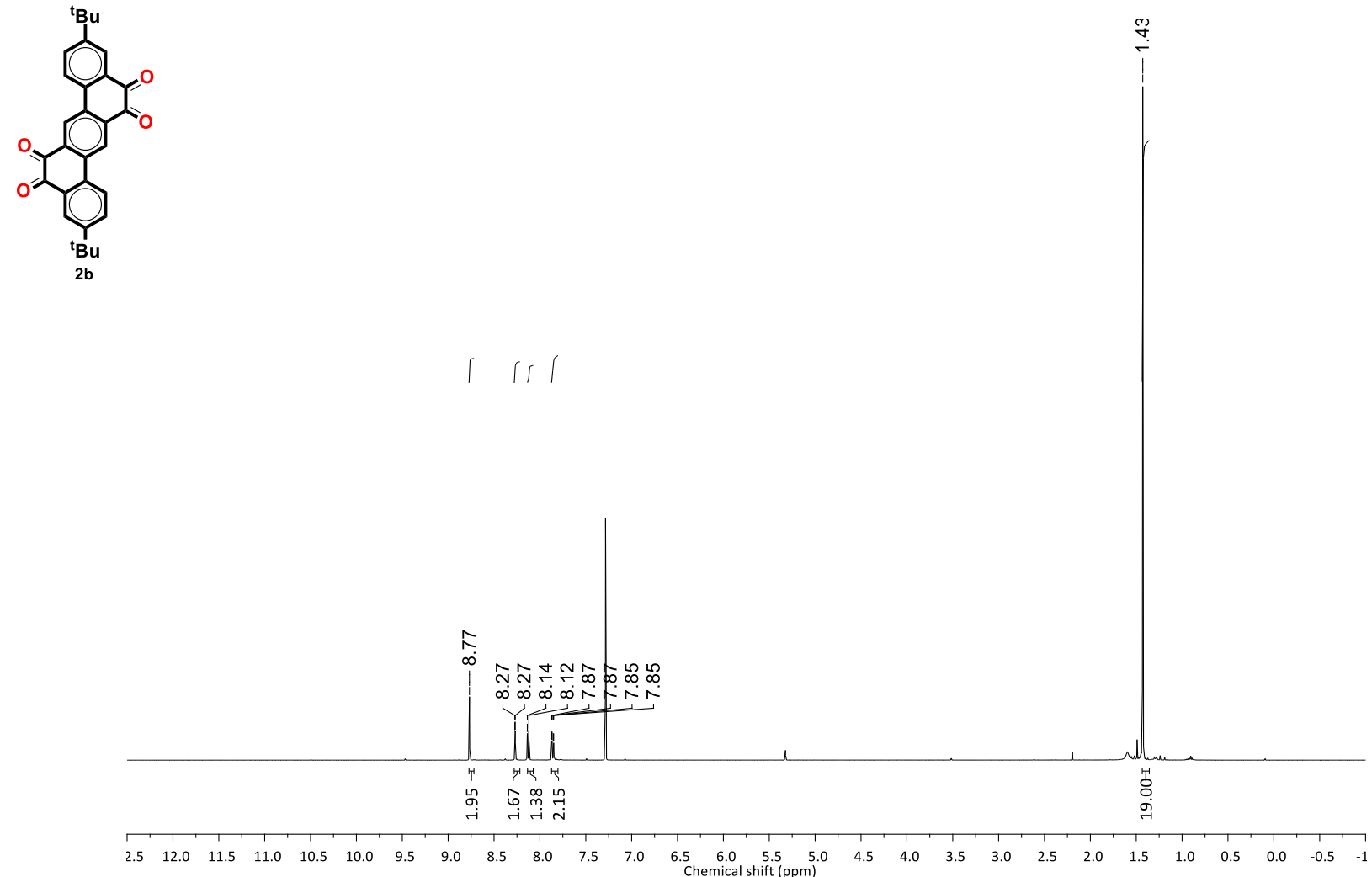

Figure S23. ${ }^{1} \mathrm{H}-\mathrm{NMR}$ of product $\mathbf{2 b}$ in $\mathrm{CDCl}_{3}(400 \mathrm{MHz})$.

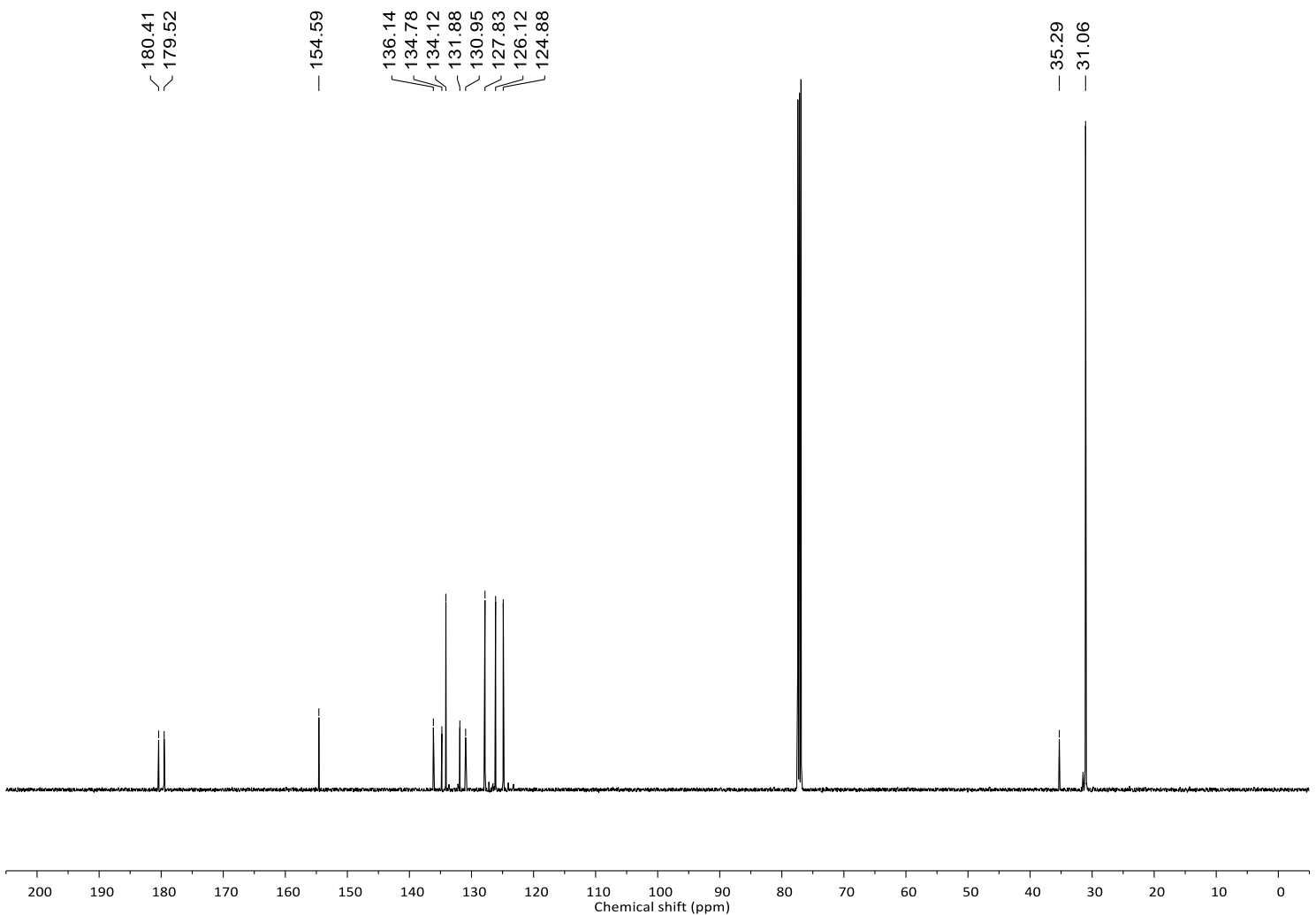

Figure S24. ${ }^{13} \mathrm{C}-\mathrm{NMR}$ of product $\mathbf{2 b}$ in $\mathrm{CDCl}_{3}(125 \mathrm{MHz})$. 

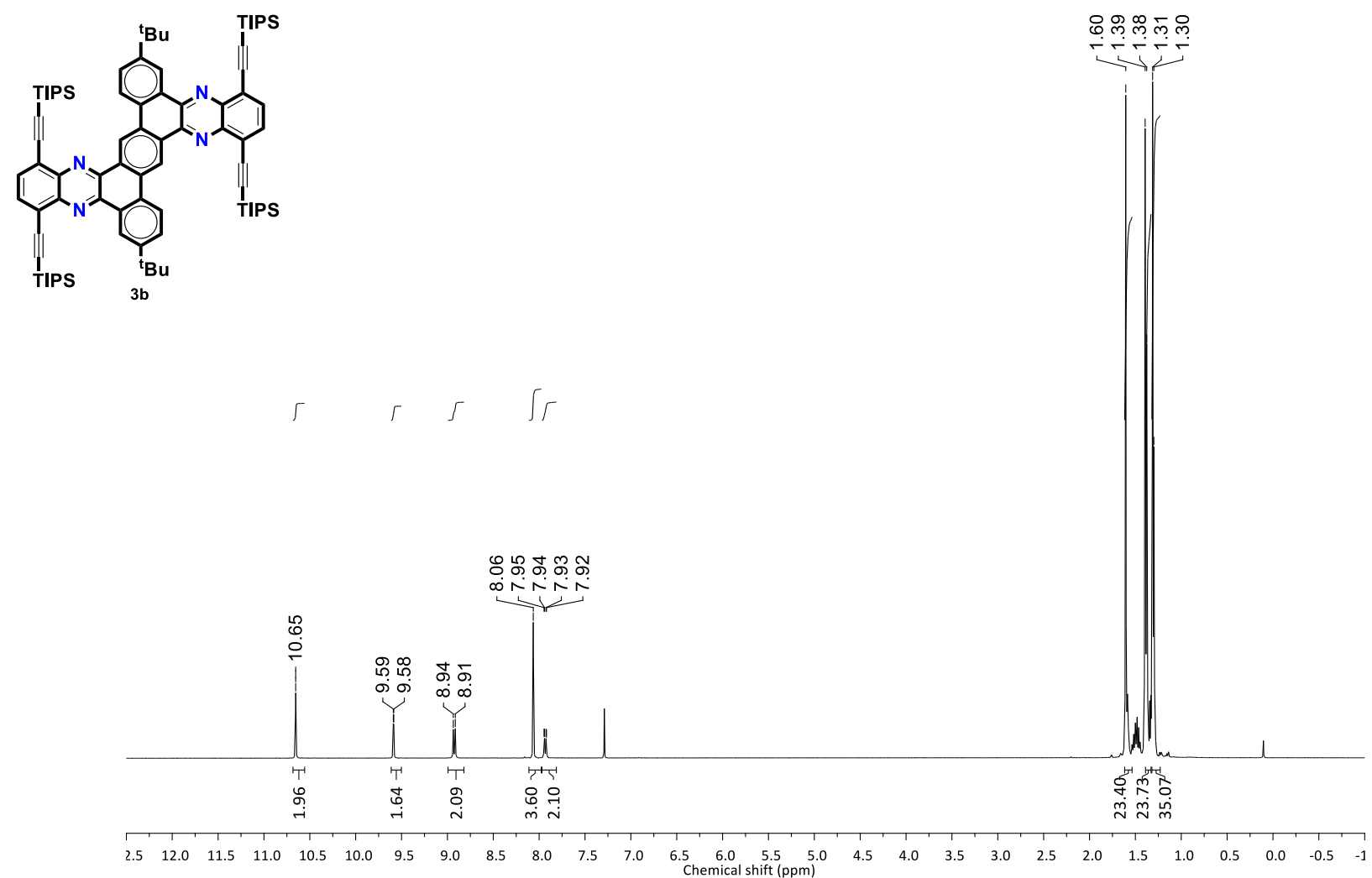

Figure S25. ${ }^{1} \mathrm{H}-\mathrm{NMR}$ of product $\mathbf{3 b}$ in $\mathrm{CDCl}_{3}(400 \mathrm{MHz})$.

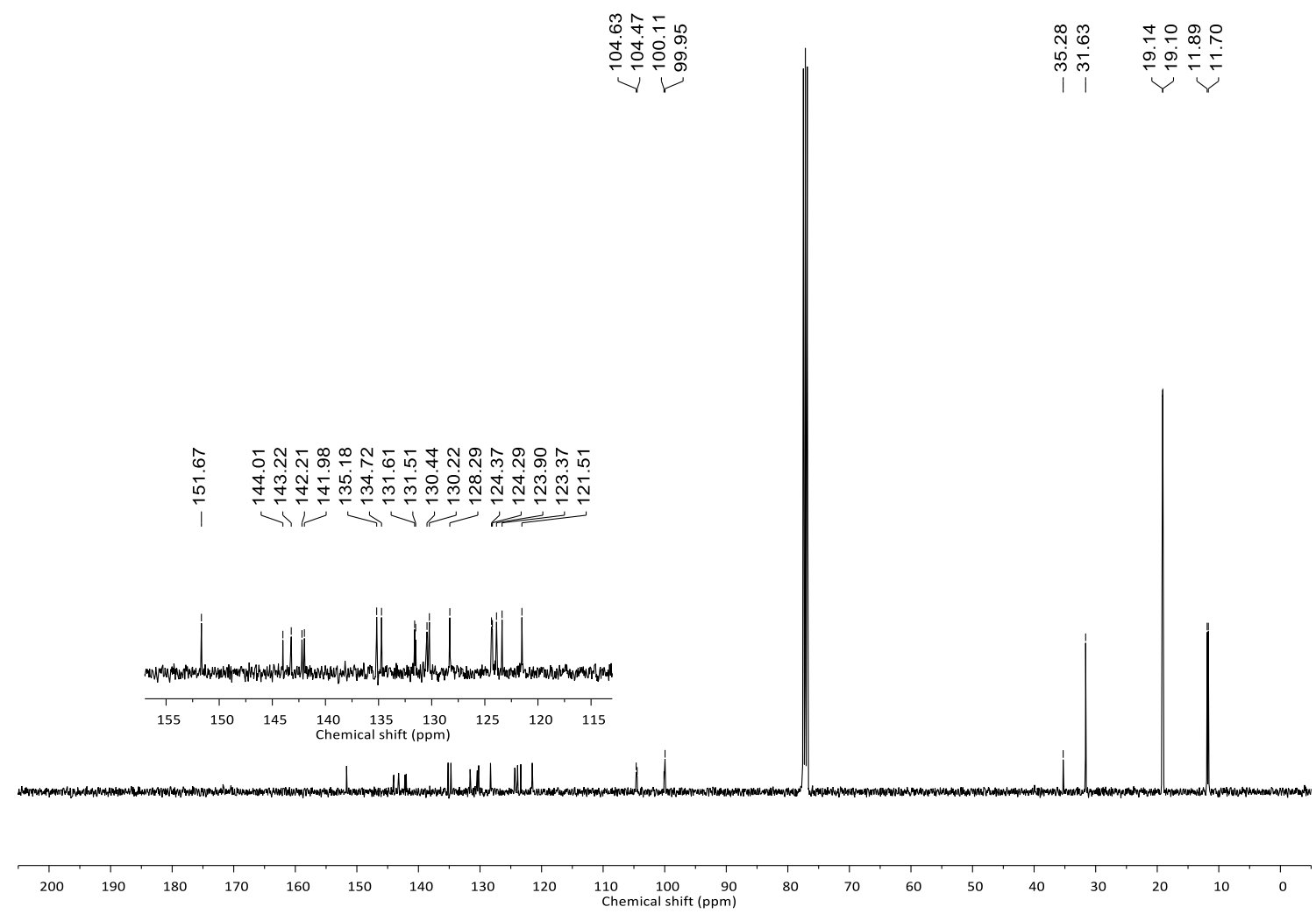

Figure S26. ${ }^{13} \mathrm{C}-\mathrm{NMR}$ of product $\mathbf{3 b}$ in $\mathrm{CDCl}_{3}(125 \mathrm{MHz})$. 

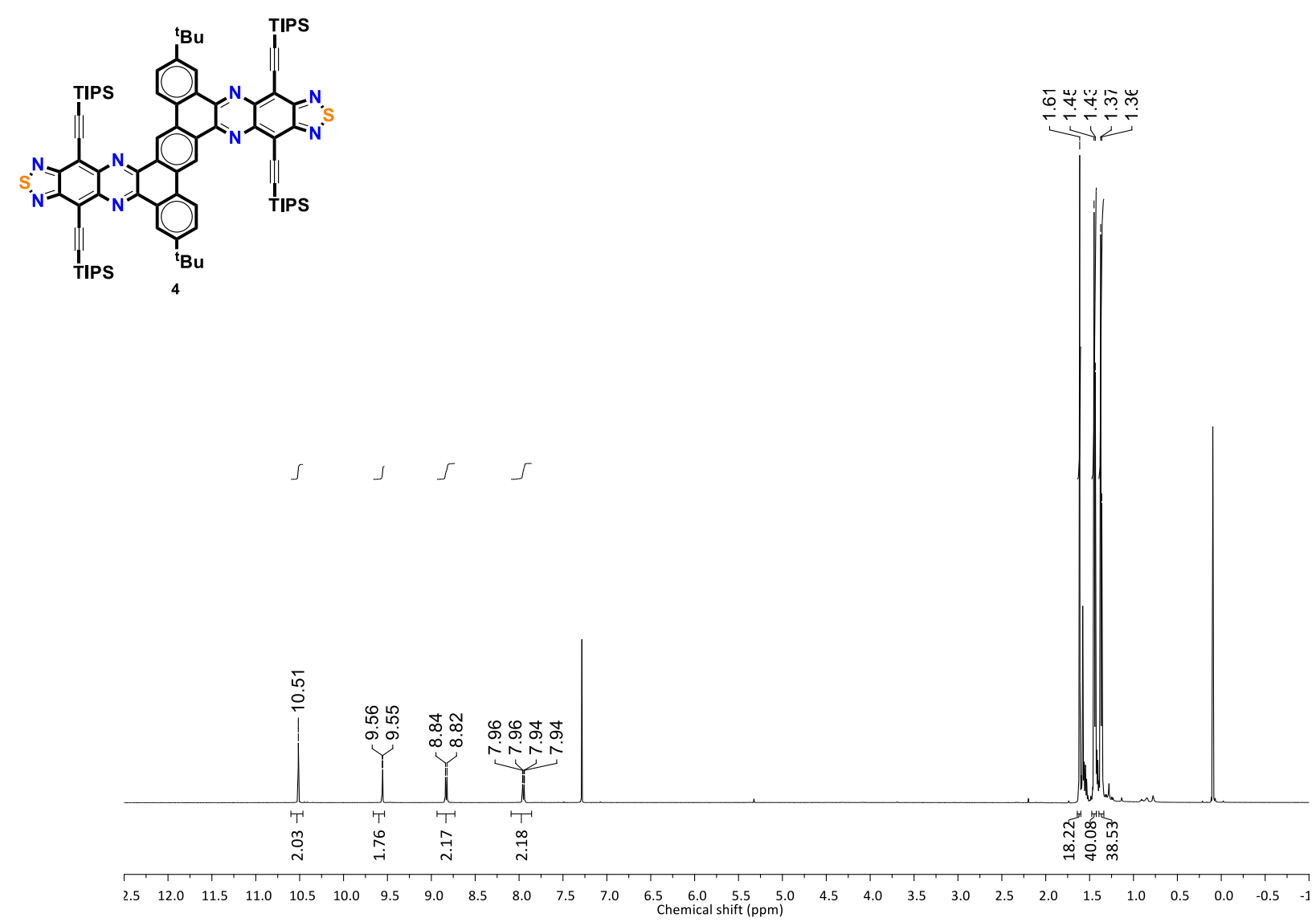

Figure S27. ${ }^{1} \mathrm{H}-\mathrm{NMR}$ of product 4 in $\mathrm{CDCl}_{3}(400 \mathrm{MHz})$.

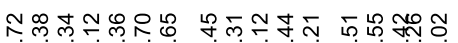

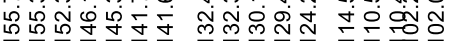

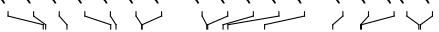

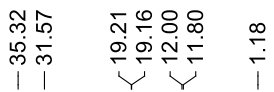

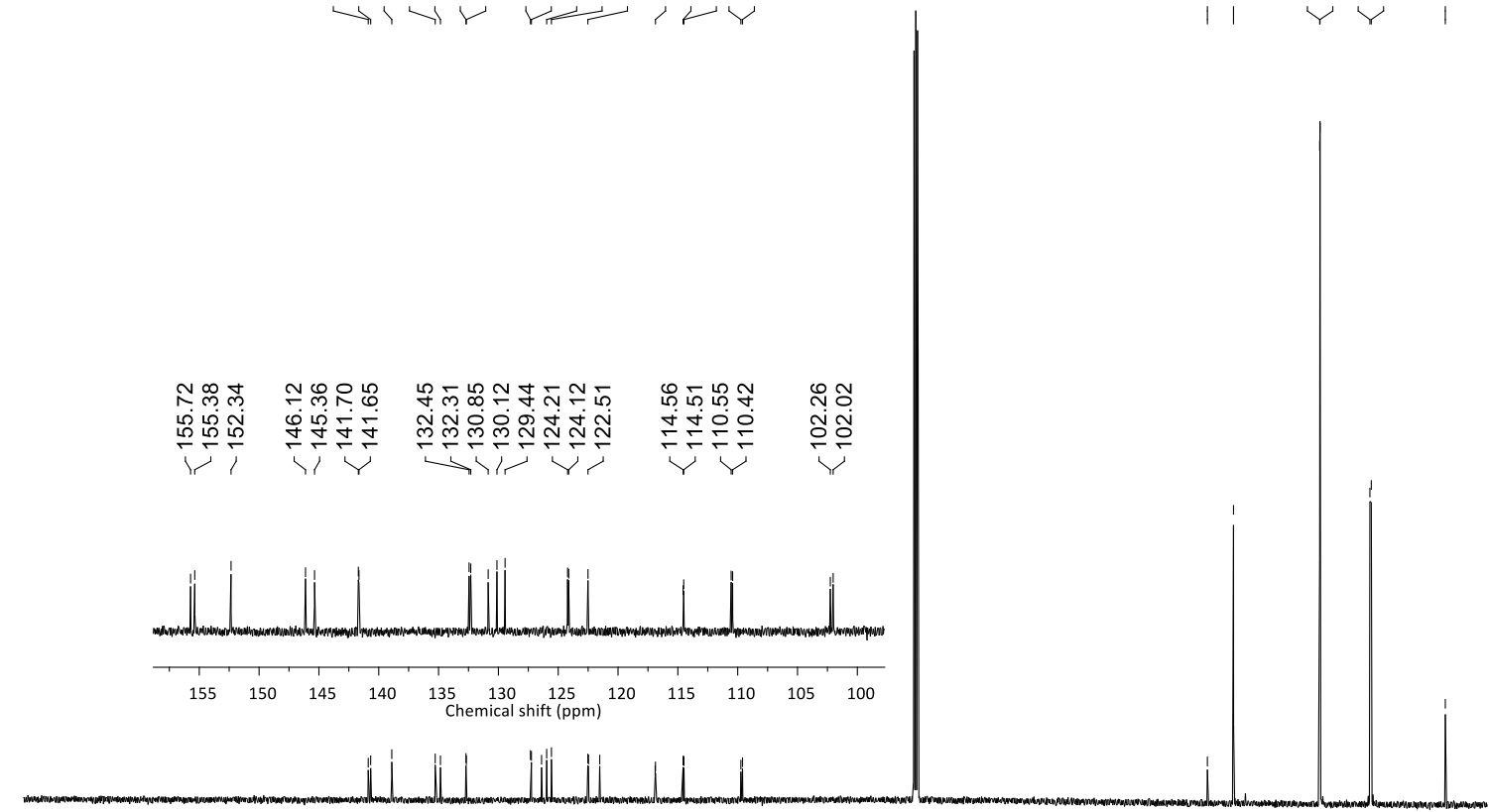

$\begin{array}{llllllllll}200 & 190 & 180 & 170 & 160 & 150 & 140 & 130 & 120 & \begin{array}{l}110 \\ \text { Chemical shift (ppm) }\end{array}\end{array}$

Figure S28. ${ }^{13} \mathrm{C}-\mathrm{NMR}$ of product 4 in $\mathrm{CDCl}_{3}(125 \mathrm{MHz})$. 

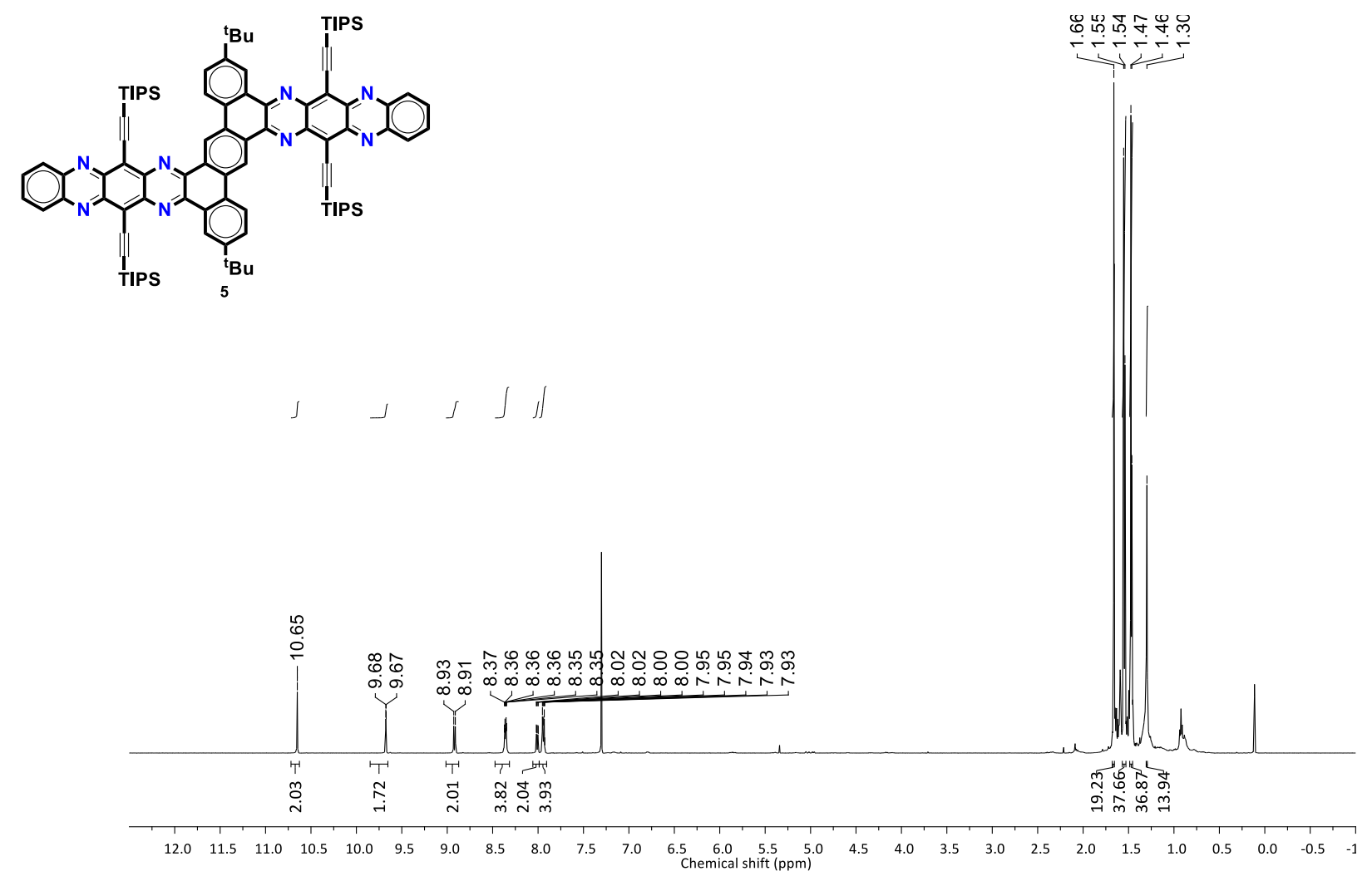

Figure S29. ${ }^{1} \mathrm{H}-\mathrm{NMR}$ of product 5 in $\mathrm{CDCl}_{3}(400 \mathrm{MHz})$.
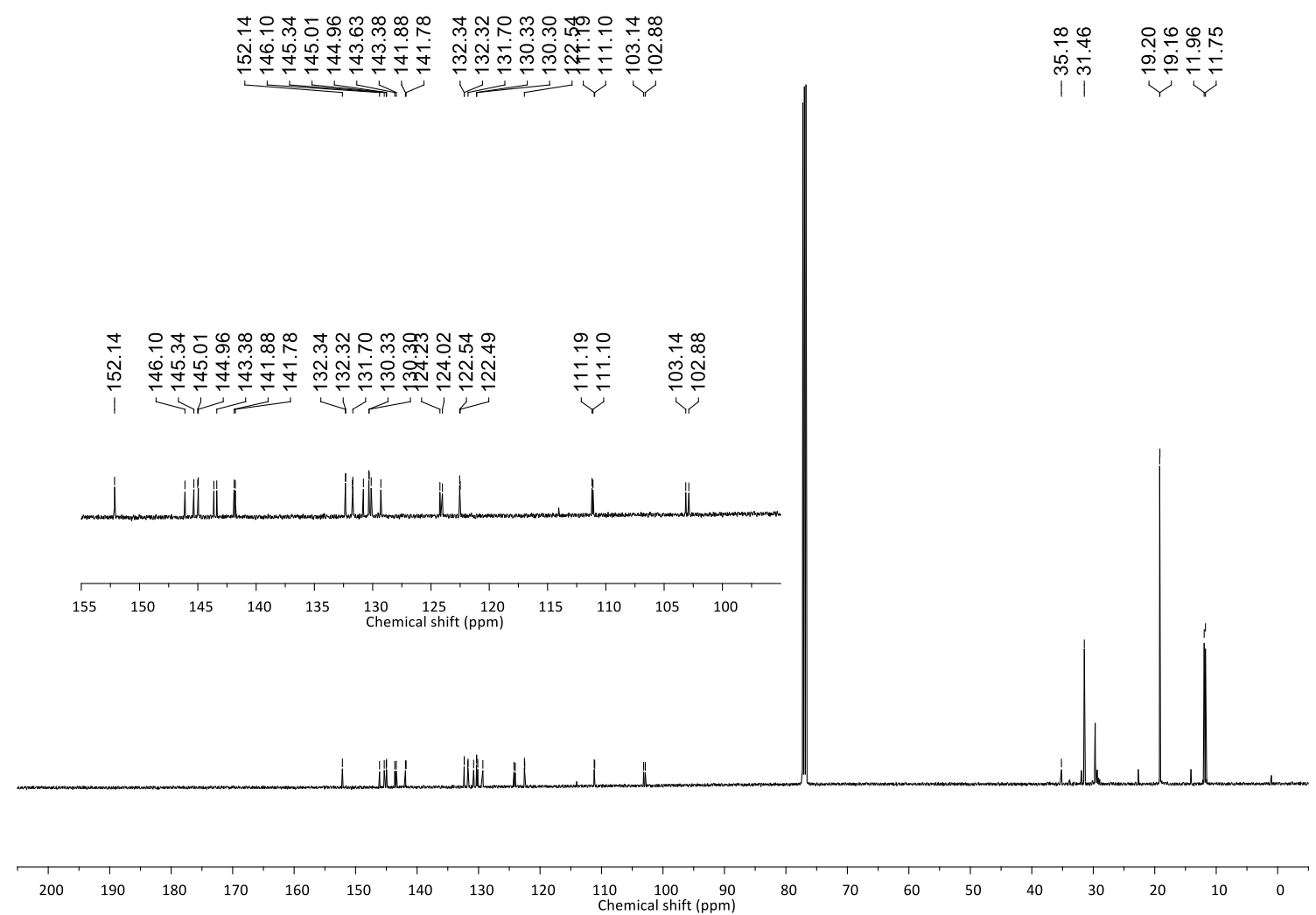

Figure S30. ${ }^{13} \mathrm{C}-\mathrm{NMR}$ of product 5 in $\mathrm{CDCl}_{3}(125 \mathrm{MHz})$. 
IR SPECTRA
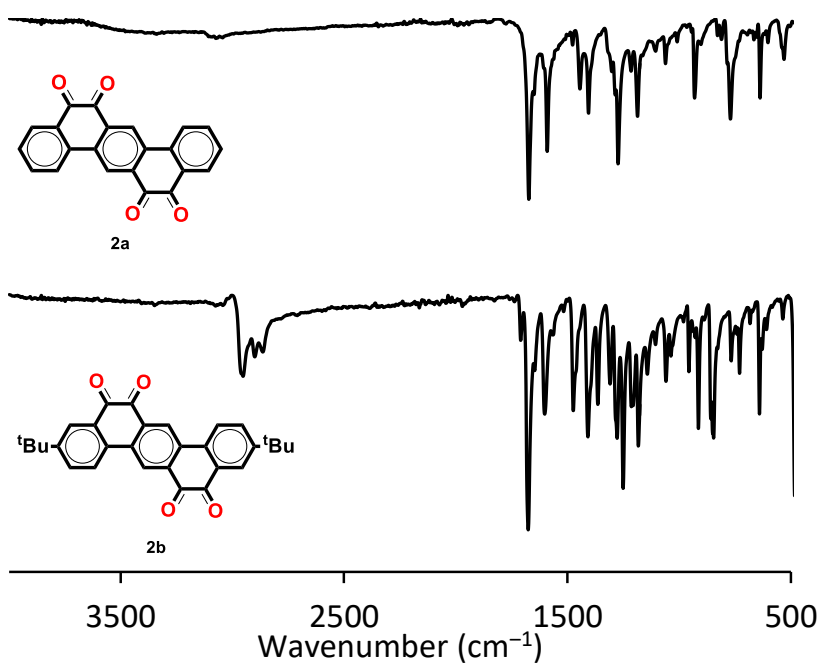

Figure S31. IR spectra of compounds $\mathbf{2 a}$ and $\mathbf{2 b}$. 


\section{X-RAY CRYSTALLOGRAPHY DATA:}

Product 3a:

Compound 3a (3 mg) was dissolved up in $\mathrm{CH}_{2} \mathrm{Cl}_{2}$ and recrystallized by liquid-liquid diffusion from $\mathrm{MeOH}$. Needle shaped crystals were obtained after three days. Afterwards, a suitable crystal was selected and placed on an Agilent SuperNova, single source at offset, Atlas diffractometer. The crystal was kept at $150.01(10) \mathrm{K}$ during data collection. Using Olex $2^{10}$, the structure was solved with the ShelXS ${ }^{11}$ structure solution program using Direct Methods and refined with the ShelXL ${ }^{12}$ refinement package using Least Squares minimisation.

Crystal structure determination of $\mathbf{3 a}$.

Crystal Data for 3a: triclinic, space group P-1 (no. 2), $\mathrm{a}=14.4215(12) \AA, \mathrm{b}=14.4364(10) \AA, \mathrm{c}=17.8777(16) \AA, \alpha=83.360(6)^{\circ}$, $\beta=73.748(7)^{\circ}, \gamma=77.318(6)^{\circ}, \mathrm{V}=3480.3(5) \AA 33, \mathrm{Z}=2, \mathrm{~T}=150.01(10) \mathrm{K}, \mu(\mathrm{CuK} \alpha)=1.125 \mathrm{~mm}-1, \mathrm{Dcalc}=1.149 \mathrm{~g} / \mathrm{cm} 3,25753$ reflections measured $\left(7.168^{\circ} \leq 2 \Theta \leq 138^{\circ}\right), 12930$ unique (Rint $=0.0901$, Rsigma $=0.1491$ ) which were used in all calculations. The final R1 was $0.0731(\mathrm{I}>2 \sigma(\mathrm{I}))$ and wR2 was 0.1804 (all data).

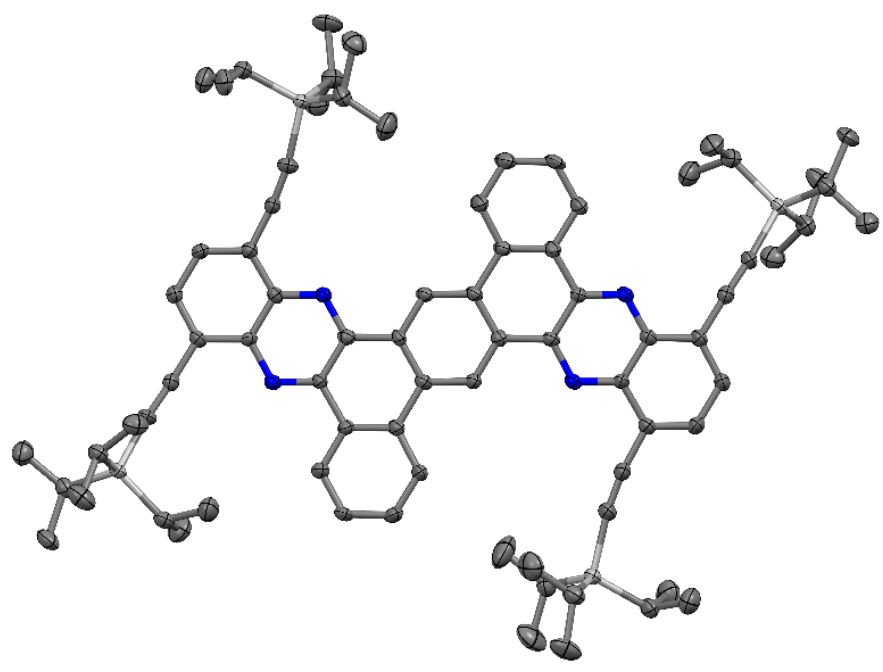

Figure S32. Thermal ellipsoid plot for compound 3a at 50\% ellipsoid contour probability. 
Table S6. Crystal data and structure refinement for compound 3a.

\begin{tabular}{|c|c|}
\hline Identification code & a20190007_JIM18134T150K \\
\hline Empirical formula & $\mathrm{C}_{78} \mathrm{H}_{98} \mathrm{~N}_{4} \mathrm{Si}_{4}$ \\
\hline Formula weight & 1203.96 \\
\hline Temperature/K & $150.01(10)$ \\
\hline Crystal system & triclinic \\
\hline Space group & $\mathrm{P}-1$ \\
\hline $\mathrm{a} / \AA$ & $14.4215(12)$ \\
\hline $\mathrm{b} / \AA$ & $14.4364(10)$ \\
\hline $\mathrm{c} / \AA ̊$ & $17.8777(16)$ \\
\hline$\alpha /^{\circ}$ & $83.360(6)$ \\
\hline$\beta /^{\circ}$ & $73.748(7)$ \\
\hline$\gamma /{ }^{\circ}$ & $77.318(6)$ \\
\hline Volume $/ \AA^{3}$ & $3480.3(5)$ \\
\hline $\mathrm{Z}$ & 2 \\
\hline$\rho_{\text {calcg }} / \mathrm{cm}^{3}$ & 1.149 \\
\hline$\mu / \mathrm{mm}^{-1}$ & 1.125 \\
\hline $\mathrm{F}(000)$ & 1300.0 \\
\hline Crystal size $/ \mathrm{mm}^{3}$ & $0.89 \times 0.092 \times 0.048$ \\
\hline Radiation & $\mathrm{CuK} \alpha(\lambda=1.54184)$ \\
\hline $2 \Theta$ range for data collection $/{ }^{\circ}$ & 7.168 to 138 \\
\hline Index ranges & $-17 \leq \mathrm{h} \leq 17,-17 \leq \mathrm{k} \leq 14,-21 \leq 1 \leq 21$ \\
\hline Reflections collected & 25753 \\
\hline Independent reflections & $12930\left[\mathrm{R}_{\text {int }}=0.0901, \mathrm{R}_{\text {sigma }}=0.1491\right]$ \\
\hline Data/restraints/parameters & $12930 / 0 / 799$ \\
\hline Goodness-of-fit on $\mathrm{F}^{2}$ & 0.965 \\
\hline Final $\mathrm{R}$ indexes $[\mathrm{I}>=2 \sigma(\mathrm{I})]$ & $\mathrm{R}_{1}=0.0731, \mathrm{wR}_{2}=0.1445$ \\
\hline Final $\mathrm{R}$ indexes [all data] & $\mathrm{R}_{1}=0.1376, \mathrm{wR}_{2}=0.1804$ \\
\hline Largest diff. peak/hole / e $\AA^{-3}$ & $0.48 /-0.41$ \\
\hline
\end{tabular}




\section{Product 3b:}

Compound $3 \mathbf{b}(5 \mathrm{mg})$ was dissolved up in $\mathrm{CH}_{2} \mathrm{Cl}_{2}$ and recrystallized by liquid-liquid diffusion from $\mathrm{MeOH}$. Needle shaped crystals were obtained after three days. Afterwards, a suitable crystal was selected and placed on an Agilent SuperNova, single source at offset, Atlas diffractometer. The crystal was kept at $150.01(10) \mathrm{K}$ during data collection. Using Olex $2^{10}$, the structure was solved with the ShelXS ${ }^{11}$ structure solution program using Direct Methods and refined with the ShelXL ${ }^{12}$ refinement package using Least Squares minimisation.

Crystal structure determination of $\mathbf{3 b}$.

Crystal Data for 3b: monoclinic, space group P2 ${ }_{1}\left(\right.$ no. 4), $a=14.6051(18) \AA, b=14.6023(12) \AA, c=20.160(3) \AA, \beta=97.200(13)^{\circ}$, $V=4265.5(9) \AA^{3}, Z=2, T=150.00(10) \mathrm{K}, \mu(\mathrm{CuK} \alpha)=0.967 \mathrm{~mm}^{-1}$, Dcalc $=1.025 \mathrm{~g} / \mathrm{cm}^{3}, 34131$ reflections measured $\left(7.07^{\circ} \leq 2 \Theta \leq\right.$ $\left.138^{\circ}\right), 12699$ unique $\left(R_{\text {int }}=0.1174, \mathrm{R}_{\text {sigma }}=0.1352\right)$ which were used in all calculations. The final $R_{1}$ was $0.0788(\mathrm{I}>2 \sigma(\mathrm{I}))$ and $w R_{2}$ was 0.2146 (all data).

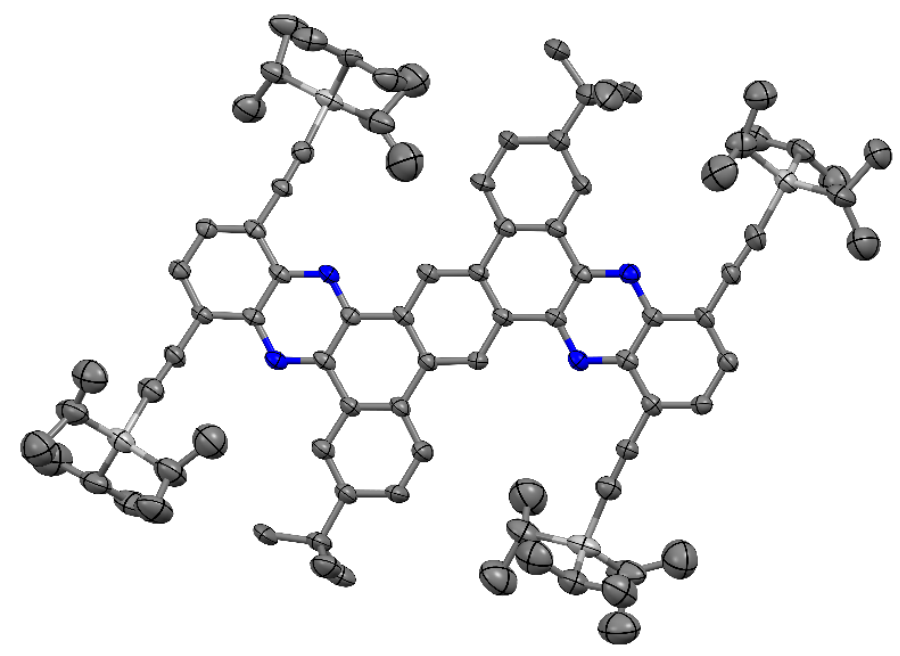

Figure S33. Thermal ellipsoid plot for compound $\mathbf{3 b}$ at $50 \%$ ellipsoid contour probability. 
Table S7. Crystal data and structure refinement for compound $3 \mathrm{~b}$.

\begin{tabular}{|c|c|}
\hline Identification code & a20190004_JIM180133T150K2 \\
\hline Empirical formula & $\mathrm{C}_{86} \mathrm{H}_{114} \mathrm{~N}_{4} \mathrm{Si}_{4}$ \\
\hline Formula weight & 1316.17 \\
\hline Temperature/K & $150.00(10)$ \\
\hline Crystal system & monoclinic \\
\hline Space group & $\mathrm{P} 21$ \\
\hline $\mathrm{a} / \AA$ & $14.6051(18)$ \\
\hline $\mathrm{b} / \AA$ & $14.6023(12)$ \\
\hline $\mathrm{c} / \AA ̊$ & $20.160(3)$ \\
\hline$\alpha /{ }^{\circ}$ & 90.0 \\
\hline$\beta /^{\circ}$ & $97.200(13)$ \\
\hline$\gamma /{ }^{\circ}$ & 90.0 \\
\hline Volume $/ \AA^{3}$ & $4265.5(9)$ \\
\hline $\mathrm{Z}$ & 2 \\
\hline$\rho_{\text {calcg }} / \mathrm{cm}^{3}$ & 1.025 \\
\hline$\mu / \mathrm{mm}^{-1}$ & 0.967 \\
\hline $\mathrm{F}(000)$ & 1428.0 \\
\hline Crystal size $/ \mathrm{mm}^{3}$ & $0.583 \times 0.314 \times 0.118$ \\
\hline Radiation & $\mathrm{CuK} \alpha(\lambda=1.54184)$ \\
\hline $2 \Theta$ range for data collection $/{ }^{\circ}$ & 7.07 to 138 \\
\hline Index ranges & $-17 \leq \mathrm{h} \leq 17,-17 \leq \mathrm{k} \leq 11,-24 \leq 1 \leq 24$ \\
\hline Reflections collected & 34131 \\
\hline Independent reflections & $12699\left[\mathrm{R}_{\text {int }}=0.1174, \mathrm{R}_{\text {sigma }}=0.1352\right]$ \\
\hline Data/restraints/parameters & $12699 / 103 / 878$ \\
\hline Goodness-of-fit on $\mathrm{F}^{2}$ & 0.971 \\
\hline Final $\mathrm{R}$ indexes $[\mathrm{I}>=2 \sigma(\mathrm{I})]$ & $\mathrm{R}_{1}=0.0788, \mathrm{wR}_{2}=0.1785$ \\
\hline Final $\mathrm{R}$ indexes [all data] & $\mathrm{R}_{1}=0.1288, \mathrm{wR}_{2}=0.2146$ \\
\hline Largest diff. peak/hole / e $\AA^{-3}$ & $0.66 /-0.34$ \\
\hline
\end{tabular}




\section{Product 4:}

Compound 4 (9 mg) was dissolved up in $\mathrm{CH}_{2} \mathrm{Cl}_{2}$ and recrystallized by liquid-liquid diffusion from $\mathrm{MeOH}$. Needle shaped crystals were obtained after three days. Afterwards, a suitable crystal was selected and placed on an Agilent SuperNova, single source at offset, Atlas diffractometer. The crystal was kept at $150.01(10) \mathrm{K}$ during data collection. Using Olex $2^{10}$, the structure was solved with the ShelXS ${ }^{11}$ structure solution program using Direct Methods and refined with the ShelXL ${ }^{12}$ refinement package using Least Squares minimisation.

Crystal structure determination of 4 .

Crystal Data for 4: triclinic, space group P-1 (no. 2), $\mathrm{a}=17.4140(9) \AA, \mathrm{b}=20.0991(17) \AA, \mathrm{c}=20.8980(18) \AA, \alpha=99.233(7)^{\circ}, \beta=$ $12.874(6)^{\circ}, \gamma=107.208(6)^{\circ}, \mathrm{V}=6114.2(9) \AA 3, \mathrm{Z}=2, \mathrm{~T}=150.01(10) \mathrm{K}, \mu(\mathrm{CuK} \alpha)=1.521 \mathrm{~mm}-1, \mathrm{Dcalc}=1.167 \mathrm{~g} / \mathrm{cm} 3,45541$ reflections measured $\left(6.91^{\circ} \leq 2 \Theta \leq 137.984^{\circ}\right), 22694$ unique $($ Rint $=0.1893$, Rsigma $=0.2690)$ which were used in all calculations. The final R1 was $0.1317(\mathrm{I}>2 \sigma(\mathrm{I}))$ and wR2 was 0.4600 (all data).

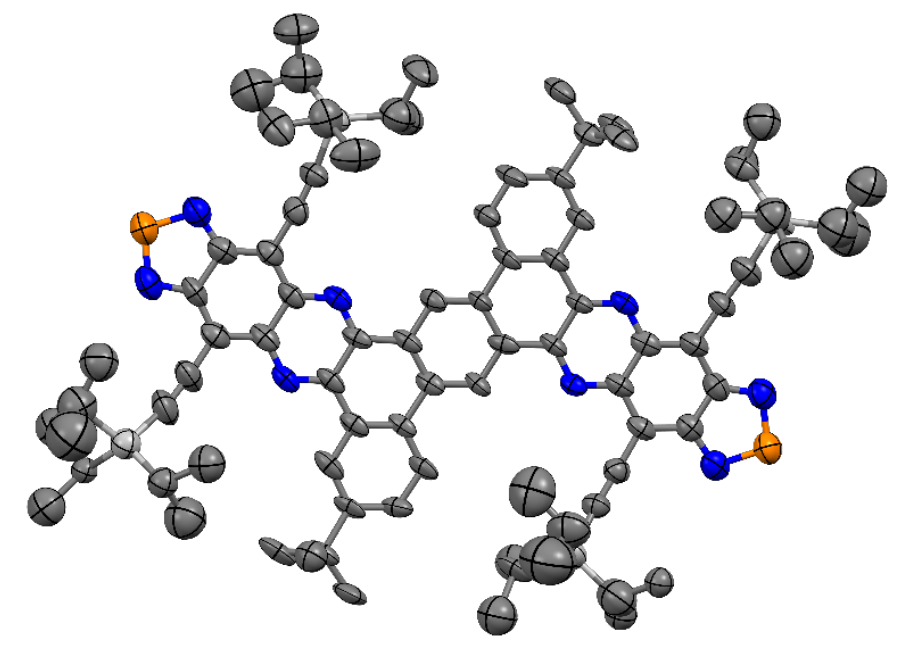

Figure S34. Thermal ellipsoid plot for compound 4 at $50 \%$ ellipsoid contour probability. 
Table S8. Crystal data and structure refinement for compound 4.

\begin{tabular}{|c|c|}
\hline Identification code & a20180082_JIM18014 \\
\hline Empirical formula & $\mathrm{C}_{129} \mathrm{H}_{165} \mathrm{~N}_{12} \mathrm{~S}_{3} \mathrm{Si}_{6}$ \\
\hline Formula weight & 2148.44 \\
\hline Temperature/K & $150.01(10)$ \\
\hline Crystal system & triclinic \\
\hline Space group & $\mathrm{P}-1$ \\
\hline $\mathrm{a} / \AA$ & $17.4140(9)$ \\
\hline $\mathrm{b} / \AA$ & 20.0991(17) \\
\hline $\mathrm{c} / \AA$ & $20.8980(18)$ \\
\hline$\alpha /^{\circ}$ & $99.233(7)$ \\
\hline$\beta /{ }^{\circ}$ & $112.874(6)$ \\
\hline$\gamma /{ }^{\circ}$ & $107.208(6)$ \\
\hline Volume $/ \AA^{3}$ & $6114.2(9)$ \\
\hline $\mathrm{Z}$ & 2 \\
\hline$\rho_{\text {calcg }} / \mathrm{cm}^{3}$ & 1.167 \\
\hline$\mu / \mathrm{mm}^{-1}$ & 1.521 \\
\hline $\mathrm{F}(000)$ & 2310.0 \\
\hline Radiation & $\mathrm{CuK} \alpha(\lambda=1.54184)$ \\
\hline $2 \Theta$ range for data collection ${ }^{\circ}$ & 6.91 to 137.984 \\
\hline Index ranges & $-21 \leq \mathrm{h} \leq 18,-24 \leq \mathrm{k} \leq 24,-25 \leq 1 \leq 24$ \\
\hline Reflections collected & 45541 \\
\hline Independent reflections & $22694\left[\mathrm{R}_{\text {int }}=0.1893, \mathrm{R}_{\text {sigma }}=0.2690\right]$ \\
\hline Data/restraints/parameters & $22694 / 380 / 1468$ \\
\hline Goodness-of-fit on $\mathrm{F}^{2}$ & 0.955 \\
\hline Final $\mathrm{R}$ indexes $[\mathrm{I}>=2 \sigma(\mathrm{I})]$ & $\mathrm{R}_{1}=0.1317, \mathrm{wR}_{2}=0.3183$ \\
\hline Final $\mathrm{R}$ indexes [all data] & $\mathrm{R}_{1}=0.3079, \mathrm{wR}_{2}=0.4600$ \\
\hline Largest diff. peak/hole / e $\AA^{-3}$ & $0.73 /-0.92$ \\
\hline
\end{tabular}

Alert level A:

PLAT026_ALERT_3_A Ratio Observed / Unique Reflections (too) Low. 25\% Check

PLAT084_ALERT_3_A HighwR2 Value (i.e. > 0.25). 0.46 Report

The crystals have good but very weak reflections. Several measurements are made but always the intensity that is obtained is very low, although a lot of exposure time is used. Due to this low intensity of diffraction there is a low relation between the observed and unique reflections.

There is a large disorder in the methyl groups in parts of the molecule along the structure. Restrictions of distance and angles, as well as restrictions in the ellipsoids are used to model the disorders. The low quality of the data obtained in the measurements and all this does not allow to reach better acorded factors. 


\section{Product 5:}

Compound 5 ( $7 \mathrm{mg}$ ) was dissolved up in $\mathrm{CH}_{2} \mathrm{Cl}_{2}$ and recrystallized by liquid-liquid diffusion from $\mathrm{MeOH}$. Needle shaped crystals were obtained after three days. Afterwards, a suitable crystal was selected and placed on an Agilent SuperNova, single source at offset, Atlas diffractometer. The crystal was kept at $150.01(10) \mathrm{K}$ during data collection. Using Olex $2^{10}$, the structure was solved with the ShelXS ${ }^{11}$ structure solution program using Direct Methods and refined with the ShelXL ${ }^{12}$ refinement package using Least Squares minimisation.

Crystal structure determination of $\mathbf{5}$.

Crystal Data for 5: triclinic, space group P-1 (no. 2), $a=9.1952(7) \AA, b=15.3983(10) \AA, c=16.9447(12) \AA, \alpha=103.841(6)^{\circ}, \beta=$ $90.728(6)^{\circ}, \gamma=99.739(6)^{\circ}, V=2292.4(3) \AA^{3}, Z=1, T=150.01(10) \mathrm{K}, \mu(\mathrm{CuK} \alpha)=0.966 \mathrm{~mm}^{-1}$, Dcalc $=1.101 \mathrm{~g} / \mathrm{cm}^{3}, 23843$ reflections measured $\left(7.016^{\circ} \leq 2 \Theta \leq 137.996^{\circ}\right), 7154$ unique $\left(R_{\text {int }}=0.0745, R_{\text {sigma }}=0.0863\right)$ which were used in all calculations. The final $R_{1}$ was $0.1174(\mathrm{I}>2 \sigma(\mathrm{I}))$ and $w R_{2}$ was 0.3869 (all data).

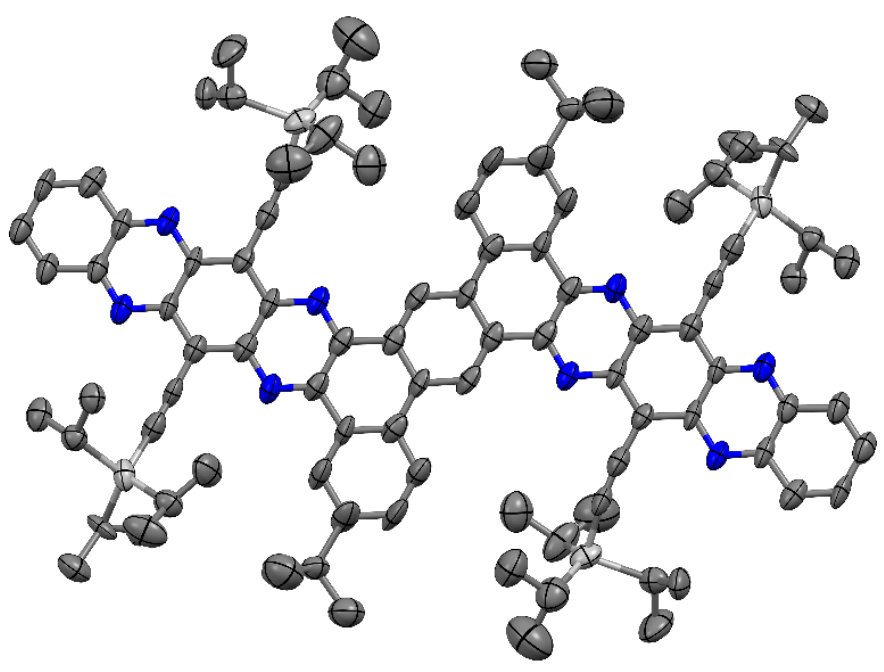

Figure S35. Thermal ellipsoid plot for compound $\mathbf{5}$ at $50 \%$ ellipsoid contour probability. 
Table S9. Crystal data and structure refinement for compound 5.

\begin{tabular}{|c|c|}
\hline Identification code & a20180092_jim18025suc \\
\hline Empirical formula & $\mathrm{C}_{98} \mathrm{H}_{118} \mathrm{~N}_{8} \mathrm{Si}_{4}$ \\
\hline Formula weight & 1520.36 \\
\hline Temperature/K & $150.01(10)$ \\
\hline Crystal system & triclinic \\
\hline Space group & P-1 \\
\hline $\mathrm{a} / \AA ̊$ & $9.1952(7)$ \\
\hline $\mathrm{b} / \AA$ & $15.3983(10)$ \\
\hline $\mathrm{c} / \AA$ & $16.9447(12)$ \\
\hline$\alpha /^{\circ}$ & $103.841(6)$ \\
\hline$\beta /{ }^{\circ}$ & $90.728(6)$ \\
\hline$\gamma /{ }^{\circ}$ & $99.739(6)$ \\
\hline Volume $/ \AA^{3}$ & $2292.4(3)$ \\
\hline Z & 1 \\
\hline$\rho_{\text {calcg }} / \mathrm{cm}^{3}$ & 1.101 \\
\hline$\mu / \mathrm{mm}^{-1}$ & 0.966 \\
\hline $\mathrm{F}(000)$ & 818.0 \\
\hline Crystal size $/ \mathrm{mm}^{3}$ & $0.717 \times 0.077 \times 0.041$ \\
\hline Radiation & $\mathrm{CuK} \alpha(\lambda=1.54184)$ \\
\hline $2 \Theta$ range for data collection ${ }^{\circ}$ & 7.016 to 137.996 \\
\hline Index ranges & $-8 \leq \mathrm{h} \leq 10,-18 \leq \mathrm{k} \leq 17,-19 \leq 1 \leq 20$ \\
\hline Reflections collected & 23843 \\
\hline Independent reflections & $7154\left[\mathrm{R}_{\text {int }}=0.0745, \mathrm{R}_{\text {sigma }}=0.0863\right]$ \\
\hline Data/restraints/parameters & $7154 / 160 / 649$ \\
\hline Goodness-of-fit on $\mathrm{F}^{2}$ & 1.194 \\
\hline Final $R$ indexes $[\mathrm{I}>=2 \sigma(\mathrm{I})]$ & $\mathrm{R}_{1}=0.1174, \mathrm{wR}_{2}=0.3287$ \\
\hline
\end{tabular}

Alert level A:

PLAT029_ALERT_3_A_diffrn_measured_fraction_theta_full value Low 0.843

The crystals have low crystallinity and diffract very weakly. The crystals are needles very difficult to separate. It is not achieved after several crystallizations better quality crystals. The low symmetry and low crystallinity does not allow to achieve measurements with completeness greater than $85 \%$. Several measurement are tried with a lot of exposure time and these are the best data that are obtained. 


\section{REFERENCES:}

(1) Brouwer Albert, M., Standards for photoluminescence quantum yield measurements in solution (IUPAC Technical Report). 2011.

(2) Rurack, K.; Spieles, M.; Anal. Chem. 2011, 83, 1232-1242.

(3) Lindner, B. D.; Engelhart, J. U.; Märken, M.; Tverskoy, O.; Appleton, A. L.; Rominger, F.; Hardcastle, K. I.; Enders, M.; Bunz, U. H. F.; Chem. Eur. J. 2012, 18, 4627-4633.

(4) Marco, A. B.; Cortizo-Lacalle, D.; Gozalvez, C.; Olano, M.; Atxabal, A.; Sun, X.; Melle-Franco, M.; Hueso, L. E.; Mateo-Alonso, A.; Chem. Commun. 2015, 51, 10754-10757.

(5) Lindner, B. D.; Engelhart, J. U.; Tverskoy, O.; Appleton, A. L.; Rominger, F.; Peters, A.; Himmel, H.-J.; Bunz, U. H. F.; Angew. Chem. Int. Ed. 2011, 50, 8588-8591.

(6) Hart, H.; Harada, K.; Du, C. J. F.; J. Org. Chem. 1985, 50, 3104-3110.

(7) Tovar, J. D.; Swager, T. M.; J. Organomet. Chem. 2002, 653, 215-222.

(8) Shen, H.-C.; Tang, J.-M.; Chang, H.-K.; Yang, C.-W.; Liu, R.-S.; J. Org. Chem. 2005, 70, 10113-10116.

(9) Wu, J.; Gherghel, L.; Watson, M. D.; Li, J.; Wang, Z.; Simpson, C. D.; Kolb, U.; Müllen, K.; Macromolecules 2003, 36, 7082-7089.

(10) Dolomanov, O. V.; Bourhis, L. J.; Gildea, R. J.; Howard, J. A. K.; Puschmann, H.; J. Appl. Crystallogr. 2009, 42, $339-341$.

(11) Sheldrick, G.; Acta Crystallographica Section A 2008, 64, 112-122.

(12) Sheldrick, G.; Acta Crystallographica Section C 2015, 71, 3-8. 